Article

\title{
Experimental Determination of the Emissivity of Powder Layers and Bulk Material in Laser Powder Bed Fusion Using Infrared Thermography and Thermocouples
}

\author{
Gunther Mohr ${ }^{1,2, *}$, Susanna Nowakowski ${ }^{3}$, Simon J. Altenburg ${ }^{1}$, Christiane Maierhofer $^{1}$ and \\ Kai Hilgenberg 1,2 \\ 1 Federal Institute for Materials Research and Testing (BAM; Bundesanstalt für Materialforschung und \\ Prüfung), Unter den Eichen 87, 12205 Berlin, Germany; Simon.Altenburg@bam.de (S.J.A.); \\ Christiane.Maierhofer@bam.de (C.M.); Kai.Hilgenberg@bam.de (K.H.) \\ 2 Institute of Machine Tools and Factory Management, Technische Universität Berlin, Straße des 17. Juni 135, \\ 10623 Berlin, Germany \\ 3 Faculty of Engineering and Natural Sciences, Technical University of Applied Sciences Wildau, \\ Hochschulring 1, 15745 Wildau, Germany; SNowakowski@gmx.de \\ * Correspondence: gunther.mohr@bam.de; Tel.: +49-030-8104-4865
}

Received: 29 October 2020; Accepted: 18 November 2020; Published: 20 November 2020

\begin{abstract}
Recording the temperature distribution of the layer under construction during laser powder bed fusion (L-PBF) is of utmost interest for a deep process understanding as well as for quality assurance and in situ monitoring means. While having a notable number of thermal monitoring approaches in additive manufacturing (AM), attempts at temperature calibration and emissivity determination are relatively rare. This study aims for the experimental temperature adjustment of an off-axis infrared (IR) thermography setup used for in situ thermal data acquisition in L-PBF processes. The temperature adjustment was conducted by means of the so-called contact method using thermocouples at two different surface conditions and two different materials: AISI 316L L-PBF bulk surface, AISI 316L powder surface, and IN718 powder surface. The apparent emissivity values for the particular setup were determined. For the first time, also corrected, closer to real emissivity values of the bulk or powder surface condition are published. In the temperature region from approximately $150{ }^{\circ} \mathrm{C}$ to $580^{\circ} \mathrm{C}$, the corrected emissivity was determined in a range from 0.2 to 0.25 for a 316L L-PBF bulk surface, in a range from 0.37 to 0.45 for $316 \mathrm{~L}$ powder layer, and in a range from 0.37 to 0.4 for IN718 powder layer.
\end{abstract}

Keywords: laser powder bed fusion (L-PBF); selective laser melting (SLM); laser beam melting (LBM); thermography; emissivity; calibration; thermocouples; 316L; IN718; process monitoring

\section{Introduction}

Additive manufacturing (AM) technologies comprise several different modern manufacturing methods. Within metallic production routes, laser powder bed fusion (L-PBF) is of outstanding interest [1]. Due to the layer-wise nature of the process, L-PBF offers unique opportunities to monitor the complete production of a part layer by layer. Numerous monitoring approaches using various technologies and diverse methodologies can be found in the relevant literature [2,3]. They are used to monitor several different objects in L-PBF, e.g., powder bed compaction [4], particle gas emissions [5], laser power [6], and thermal emissions [7]. 
In this introductory section, a brief overview is given on thermal monitoring in L-PBF and the theoretical background about emissivity of real metallic surfaces. Furthermore, a brief review on temperature adjustment attempts for thermography in AM and a short survey on oxidation and its influence on emissivity are given. In Section 1.5, the calibration approach of this study is introduced.

\subsection{Thermal Monitoring in L-PBF}

As melting, solidification and cooling are essential for L-PBF, thermal aspects of the component during manufacturing are of utmost interest. Transient heat flux and thermal history directly affect part quality and properties of L-PBF components. Therefore, the most applied monitoring approaches deal with the spatial and temporal monitoring of heat radiation of the built-up [8]. Among the approaches of thermal condition monitoring, contactless measurement techniques are most common. Passive infrared (IR) thermography is a technology which was used by several groups of authors for thermal in situ process monitoring means [7,9-14]. IR thermography can acquire data of thermal emissions of the process layer by layer with variations in spatial and temporal resolutions, depending on the particular equipment and setup [12]. Compared to highly localized pyrometric measurements, IR cameras allow for a relatively large field of view, as well as for the capability to capture different build parts or different sections of one part at the same time without the need for an implementation that is coaxial to the laser path.

However, without appropriate calibration or adjustment of the signal of the IR camera used in the particular conditions of a specific setup, the acquired data provide information on absolute or relative radiation intensity or apparent temperatures, but not on real surface temperature values. It is interesting to note that there are currently no standardized procedures and reference standards for the calibration of infrared cameras in additive manufacturing setups. Therefore, in the following, temperature adjustment and temperature calibration are used as synonyms. This is due to the fact that the computation of temperature from data recorded with an IR camera is not only based on measured radiation intensity but highly depends on the emissivity of the target object [15]. IR cameras deliver either calculated IR signal values or apparent temperature values [13] (in the case of a previous black body calibration of the camera itself), or they deliver IR signals proportional to the radiant flux absorbed by the camera detector [16] (in the case of no previous black body calibrations or no computational considerations of such a forgone calibration). Commercial IR thermography cameras are often calibrated for black body radiation by their manufacturer. In these cases, the IR signal values, delivered by the camera, are sometimes referred as apparent temperatures, as done by the authors in other work [12]. These apparent temperatures are well below the actual temperatures of the regarded surfaces. The discrepancy between real temperatures and these apparent temperatures is mainly a result of differences in emissivity of real surfaces and black body radiators [15] on the one hand, and additional attenuation effects by optical elements in the optical path between camera and object in the particular scenery on the other hand $[9,12]$.

Depending on the monitoring goal, the use of IR thermography without determination of real temperatures due to a missing calibration of the setup can still be very valuable, as for many issues the relative comparison of apparent temperatures or cooling rates can already provide enough informative value for particular conclusions, e.g., defect detection $[7,12,16]$ or detection of areas of heat accumulation $[7,13,17]$. Therefore, the knowledge of an absolute temperature is not always necessary, especially when IR thermography is used as comparative mean against a kind of standard condition. However, there are also several research questions in which the knowledge of a calibrated absolute temperature or at least a reliable approximation of the absolute temperature would be desirable, e.g., in the field of validations of numerical modelling [18] or for considerations and classifications of in situ heat treatments during the L-PBF process [13]. Hence, a calibration of an installed IR camera at a L-PBF machine is considered to be very useful. 


\subsection{Theoretical Background about Emissivity or Real Metallic Surfaces}

According to Usamentiaga et al. [15], the most important calibration parameter for temperature measurement using IR thermography is emissivity. They reported a general procedure to measure emissivity, i.e., the so-called contact method. This method uses a thermocouple to acquire a reference temperature of the target object, which is heated up to a temperature of real working conditions. At these conditions, the apparent temperature of the IR camera can be calibrated against the temperature of the thermocouple.

Hereafter, a brief excursus into the theoretical background and definition of emissivity is given and the introduced equations will be used in subsequent sections: The radiosity $W_{\lambda b}$ of a black body (a black body is defined by transmittance $\tau=0$ and reflectance $\rho=0$; hence, absorptance $\alpha=1$, and thus its radiosity equals its radiant exitance) is a function of temperature $T$ and wavelength $\lambda$ and can be described by Planck's law, where $c_{1}$ and $c_{2}$ are radiation constants $[15,19]$. The peak intensities for higher temperatures are shifted towards smaller wavelengths. The shift can be explained by Wien's displacement law. Both is graphically illustrated in Figure 1.

$$
W_{\lambda b}(\lambda, T)=\frac{c_{1}}{\lambda^{5}} \frac{1}{\exp \left(\frac{c_{2}}{\lambda \cdot T}\right)-1}
$$

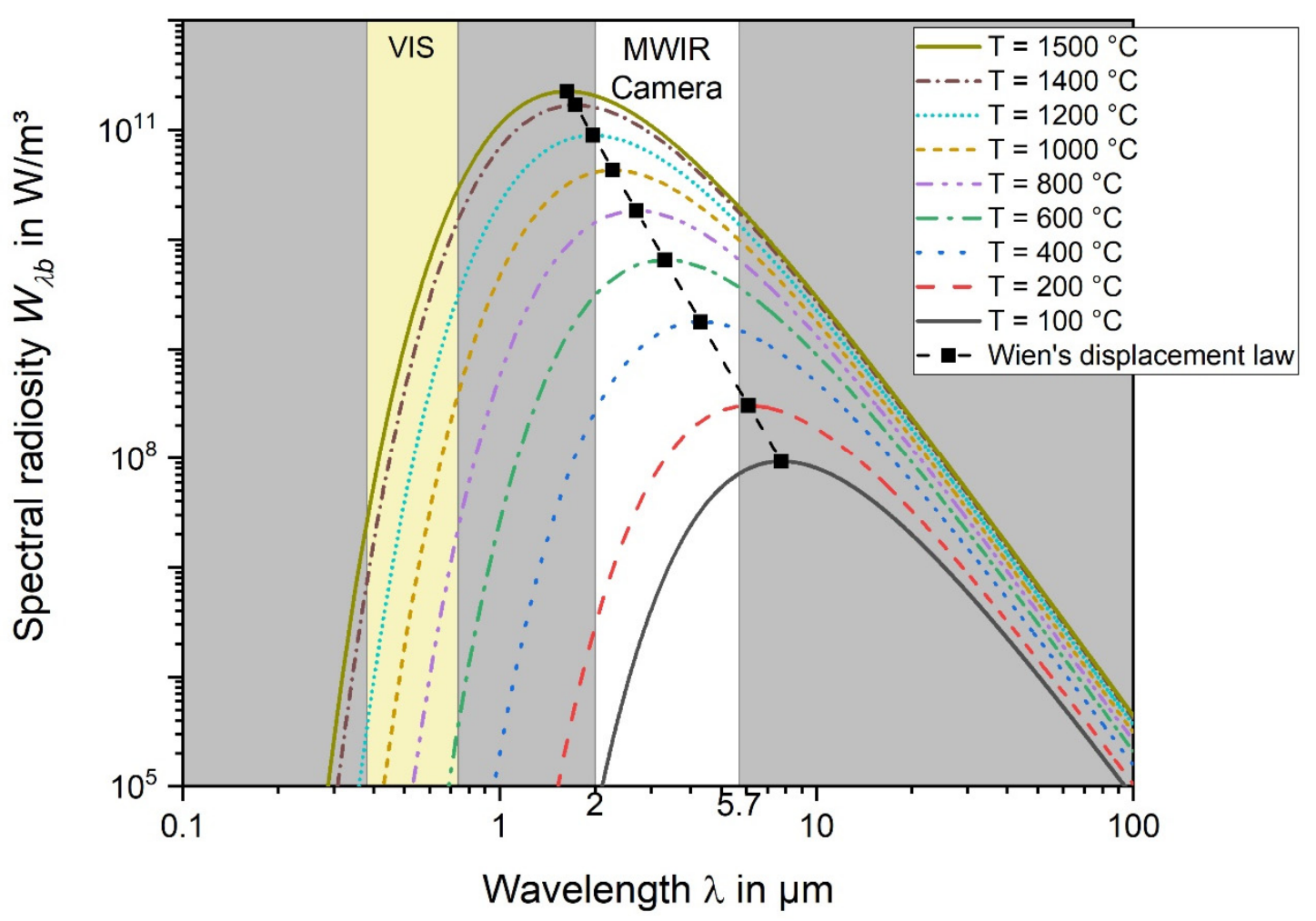

Figure 1. Planck's law and Wien's displacement law graphically expressed. The visible spectrum (VIS) and the mid-wavelength infrared (MWIR) region of the camera of this study are highlighted.

It is worth noticing from Figure 1 that the most relevant temperature regions of solidified surface temperatures of L-PBF parts during cooling down after laser exposure as well as in the pre-heating condition prior to laser exposure have their maximum intensity in the mid-wavelength infrared (MWIR) region. As also summarized by Usamentiaga et al. [15], the integration of Planck's law through all 
wavelengths leads to the radiant exitance of a blackbody and can be defined as in Equation (2), where $\sigma$ is the Stefan-Boltzmann constant $\left(\sigma=5.6704 \ldots \times 10^{-8} \mathrm{~W} /\left(\mathrm{m}^{2} \mathrm{~K}^{4}\right)\right)$.

$$
W_{b, t o t a l}=\sigma T^{4}
$$

For the determination of the spectral emissivity, a computation of the spectral exitance is required. An integration over all wavelengths, leading to Equation (2), would be an ineligible simplification in the case of the restricted spectrum of wavelengths in thermographic applications. As IR sensors are always sensitive in a restricted spectral range only, an integration of Planck's law over the appropriate wavelengths is required. Figure 2 shows the difference in calculations for an integration over $2 \mu \mathrm{m}$ to $5.7 \mu \mathrm{m}$ (comparable to the spectral range of the sensor used in this study) compared to the Stefan-Boltzmann approach. This demonstrates clearly that the use of Stefan-Boltzmann would lead to significant errors.

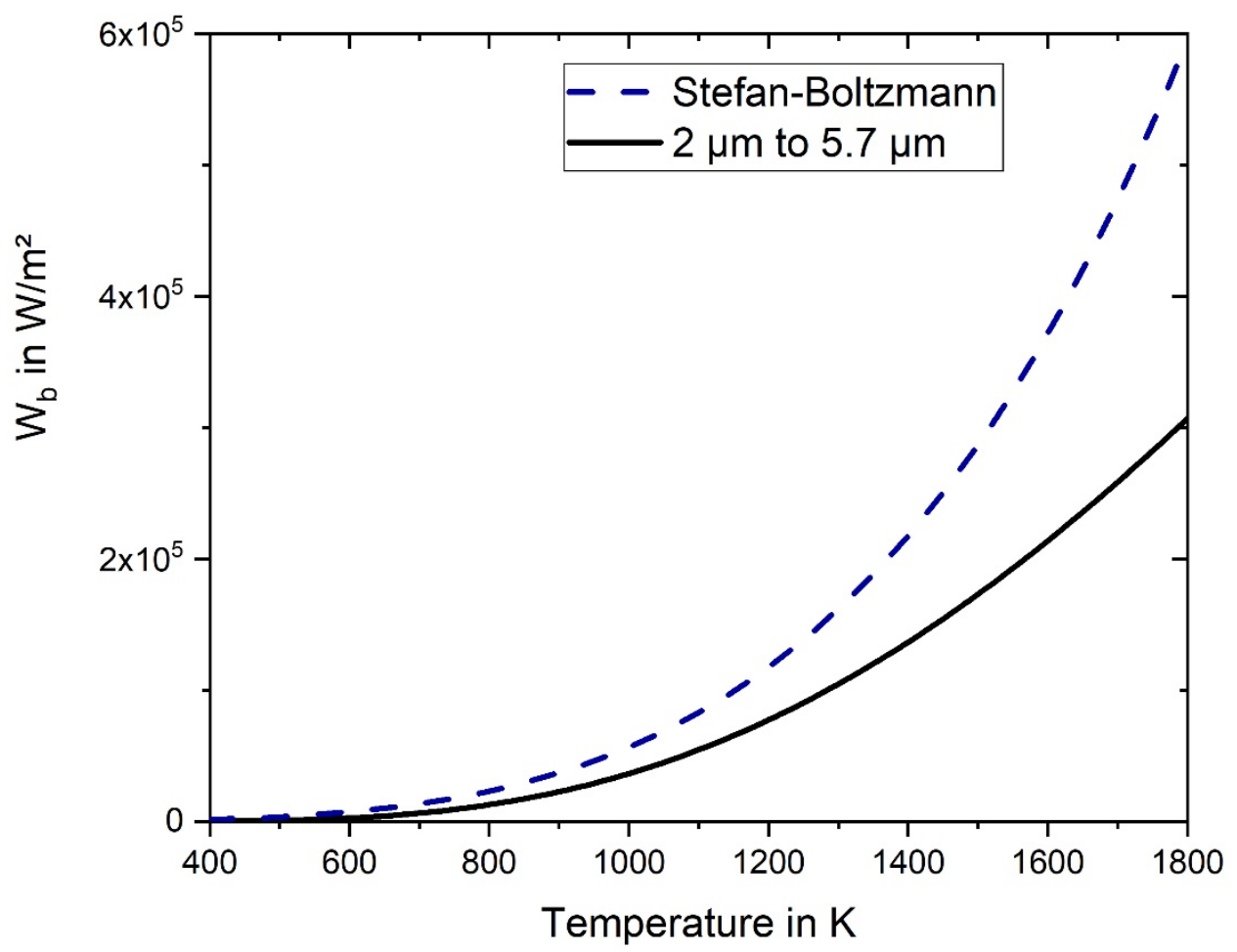

Figure 2. Theoretical calculations of radiant exitance $W_{b}$ using the Stefan-Boltzmann approach and an integration through a limited spectrum of wavelengths.

Real surfaces do not fulfill the definition of a black body. They always emit less energy than a black body. The ratio of the spectral exitance of a real body $W_{\lambda r}$ to that of a black body $W_{\lambda b}$ at the same temperature is defined as spectral emissivity $\varepsilon_{\lambda}$, see Equation (3).

$$
\varepsilon_{\lambda}(\lambda)=\frac{W_{\lambda r}(\lambda)}{W_{\lambda b}(\lambda)}
$$

The emissivity of a black body is $\varepsilon=1$, the emissivity of real bodies is smaller $(\varepsilon<1)$. For simplification reasons, the emissivity $\varepsilon$ of solid objects is often treated as a constant and independent of the wavelength within short intervals, in which IR sensors work [15]. In doing so, real bodies are assumed to be grey bodies [15].

In the case of unknown transmission losses of the optical path between sensor and target object in a specific experimental setup, a calculation of the emissivity based on measured reference temperatures 
and apparent temperatures of an IR camera would result in an apparent emissivity $\varepsilon_{a p p}$ of the target object in the particular scenery which is smaller than the actual emissivity of the target object $\varepsilon_{\text {real }}$.

As the aim of this work was the temperature adjustment of a specific MWIR camera setup used as thermal monitoring device at a particular L-PBF system, thereafter, $\varepsilon_{a p p}$ was used in the further considerations in a first stage. This simplified the analysis, as the transmission losses of the optical elements were neglected under the assumption of being constant over the respective temperature regions. These have often been referred to as being influential factors on emissivity, e.g., by Lane et al. [9]. In a second stage, a correction of transmission losses and a consideration of radiation of the ambient temperature were conducted to calculate an approximation of the real emissivity of the target object $\varepsilon_{\text {corr }}$, although still within the grey body approximation.

The emissivity of a real target object depends on several factors: material, surface condition (surface roughness and oxidation state), viewing angle, temperature and wavelength [20]. The published reference values of emissivity of different materials in data sheets are usually considered as being captured perpendicular to the surface of the target object [21]. Metals and their alloys have considerably low emissivity values and undergo heavy variations due to their surface conditions [22], e.g., polished steel sheets have $\varepsilon=0.1$ at a temperature of $T=310^{\circ} \mathrm{C}$, but in aged and oxidized condition, they show an emissivity of up to $\varepsilon=0.8$. For stainless steel AISI 316 in polished condition, one can find emissivity values between 0.24 and 0.31 in a temperature range of $200{ }^{\circ} \mathrm{C}$ to $1040{ }^{\circ} \mathrm{C}$ [21].

\subsection{Calibration Attempts for Thermography in Additive Manufacturing}

Within the scope of IR thermography in AM, some work has been published that includes attempts to calibrate a particular IR camera setup or to evaluate emissivities for particular process conditions. The differences of the cooling rate of the transition between liquidus and solidus in the melt pool can be used as a kind of single-point calibration in cases where the temporal or spatial resolution of the camera allows for reliable capturing of this condition. This was done by Doubenskaia et al. [23] for laser metal deposition (LMD) using TiAl6V4. They used an IR camera sensitive in a spectral range from $3 \mu \mathrm{m}$ to $5 \mu \mathrm{m}$ and calculated an emissivity of $\varepsilon=0.201$ at the transition temperature. Yadroitsev et al. [24] also used the liquidus solidus transition during a L-PBF process using TiAl6V4. They used a CCD camera setup coaxial to the laser path and measured at a wavelength of $0.8 \mu \mathrm{m}$. They calculated an emissivity of $\varepsilon=0.35$ at the transition temperature. Heigel and Whitenton [25] determined the liquidus-solidus transition for the calibration of a SWIR camera monitoring the L-PBF process of the nickel-based alloy IN625. Additionally, they calculated the effective emissivity of a L-PBF IN625 surface as $\varepsilon=0.168$, based on the transition temperatures [25]. Other work by Lane et al. [9] argued for using assumption-based estimations of uniform emissivity values of $\varepsilon=0.5$ as long as no measured emissivity values are available and in order to still use temperature values instead of IR signal values.

As mentioned above, a possible approach for transforming IR signals or apparent temperatures of IR cameras into real temperatures is the synchronous use of a second but already calibrated temperature measuring technique during IR capturing, which measures the temperature of the object of investigation directly as a reference. The classic approach for this is the contact method, using thermocouples (TC) for reference temperature measurement. There is only limited work published on this for L-PBF. Heigel et al. [26] and Williams et al. [14] presented calibration results of the contact method for their specific camera setups.

Williams et al. [14] installed an IR camera of type A 35 (FLIR Systems Inc., Wilsonville, OR, USA) in the build chamber of a commercial L-PBF system of type AM250 (Renishaw plc, Wotton-under-Edge, UK) using an observation angle of $24^{\circ}$ (detector plane to build plane). The resulting resolution of their setup was approximately $1 \mathrm{~mm}^{2}$ per pixel, captured at a framerate of $60 \mathrm{~Hz}$. They used a heated AM calibration component manufactured by L-PBF using 316L with and without powder on top of it. The real surface temperature was measured by one TC. The results were directly used for a determination of in-process surface temperatures of built parts, which were monitored afterwards in the same study. They abstained from any calculation of apparent or real emissivity values. 
Heigel et al. [26] calibrated an IR camera sensitive in a reduced spectral range of $1.35 \mu \mathrm{m}$ to $1.6 \mu \mathrm{m}$ by using a purposely built calibration setup outside of a L-PBF system. Their calibration setup ensured similar conditions to their monitoring setup at a L-PBF system of type M270 (EOS GmbH, Krailing, Germany) presented by Lane et al. [9], i.e., using an observation angle of $45^{\circ}$ to $43.7^{\circ}$. They used a heated AM calibration component manufactured by L-PBF using IN625. They calculated an emissivity $\varepsilon=0.680$ of a rather smooth surface (Sa approximately $12 \mu \mathrm{m}$ ) and an emissivity $\varepsilon=0.761$ of a rather rough surface (Sa approximately $27 \mu \mathrm{m}$ ). Oxidation of IN625 was also considered, but resulted in being negligible as a factor of emissivity in their study. However, the question as to whether the not purposely oxidized specimens (post process oxidation was conducted for some specimens) might have already been oxidized during the built process remained unclear.

\subsection{Oxidation and Its Influence on Emissivity}

In the frame of this study, knowledge regarding oxidation growth at steel surfaces and its effect on emissivity in general is needed for the discussion section. Hence, a brief excursus is given hereafter, based on the relevant literature, summarizing published results on oxide layer thickness of steels and its influence on emissivity. Thickness growth of material dependent oxide layers depends on atmosphere, temperature and time. When assuming a constant atmosphere, temperature and time play important roles in the evolution of an oxide layer.

Hakiki et al. [27] measured the oxide film thickness of austenitic stainless steel AISI 304 (1.4301) tempered in the temperature range between $50^{\circ} \mathrm{C}$ and $450{ }^{\circ} \mathrm{C}$ in air for $2 \mathrm{~h}$. The film thickness varied between $8 \mathrm{~nm}\left(50{ }^{\circ} \mathrm{C}\right)$ and $30 \mathrm{~nm}\left(450{ }^{\circ} \mathrm{C}\right)$ [27].

Kämmerer [28] measured the thickness of oxide layers of cold-rolled plates of the ferritic steel AISI 441 (1.4509) tempered in air. She showed the exponential relationship between tempering temperature and oxide layer thickness. She examined a change in oxide layer growth rate between $400{ }^{\circ} \mathrm{C}$ and $500{ }^{\circ} \mathrm{C}$ towards higher growth rates for higher temperatures, at a tempering time of $10 \mathrm{~h}$. At a tempering temperature of $400{ }^{\circ} \mathrm{C}$, no significant change of oxidation thickness could be revealed between holding times of $1 \mathrm{~h}$ and $10 \mathrm{~h}$. The measured oxide layer thickness was between $3 \mathrm{~nm}$ and $3.5 \mathrm{~nm}$ at a tempering temperature of $400{ }^{\circ} \mathrm{C}$ and approximately $4 \mathrm{~nm}$ at $500{ }^{\circ} \mathrm{C}$ (holding time $10 \mathrm{~h}$ ). However, repeated tempering with interim cooling down $\left(10\right.$ times $1 \mathrm{~h}$ at $\left.400^{\circ} \mathrm{C}\right)$ resulted in doubling of the oxidation layer thickness [28].

According to Janssen [29], who studied oxidation of austenitic stainless steel AISI 304 (1.4301) in air, the literature values about the thickness of a passive oxidation layer of steels varied between $1.5 \mathrm{~nm}$ and $8 \mathrm{~nm}$ (mostly in the area $2 \mathrm{~nm}+/-0.6 \mathrm{~nm}$ ). During his oxidation experiments, a slight yellow annealing color started to be visible by eye at $550{ }^{\circ} \mathrm{C}$ ( 5 min holding time) changing to gold-yellow at $600{ }^{\circ} \mathrm{C}$ ( $9 \mathrm{~min}$ holding time) and darkened after a subsequent $10 \mathrm{~min}$ holding time at $595{ }^{\circ} \mathrm{C}$. During the temperature rise from $410{ }^{\circ} \mathrm{C}$ to $550{ }^{\circ} \mathrm{C}$, he observed a distinct increase in oxidation of chromium and iron. From approximately $580{ }^{\circ} \mathrm{C}$ and especially from $600{ }^{\circ} \mathrm{C}$, the oxidation rate of iron increased strongly, while the chromium oxidation rate increased slightly. This was in accordance with his measurements of the oxidation layer thickness: A first distinct growth of the oxidation layer was measurable after a temperature rise from $410{ }^{\circ} \mathrm{C}$ to $550{ }^{\circ} \mathrm{C}$, followed by a strong increase in the temperature region from $550{ }^{\circ} \mathrm{C}$ to $600{ }^{\circ} \mathrm{C}$. At $900{ }^{\circ} \mathrm{C}$, the oxidation layer thickness was around $35 \mathrm{~nm}$ to $65 \mathrm{~nm}$ with an additional $2 \mu \mathrm{m}$ to $3 \mu \mathrm{m}$ thick scale layer.

Iuchi et al. [30] investigated the modelling of an emissivity change during the growth of oxide layers for a wavelength of $\lambda=1.5 \mu \mathrm{m}$ at cold rolled steel tempered at $500{ }^{\circ} \mathrm{C}$. They found that the emissivity behavior of oxide films thinner than $5.8 \mathrm{~nm}$ was almost identical to that of non-oxidized surfaces. For oxide films thicker than $39.1 \mathrm{~nm}$, the emissivity behavior changed drastically from approximately $\varepsilon=0.3$ (at $5.8 \mathrm{~nm}$ ) to approximately $\varepsilon=0.7$ (at $39.1 \mathrm{~nm}) ; \varepsilon=0.8($ at $54.2 \mathrm{~nm}) ; \varepsilon=0.87$ (at $82.7 \mathrm{~nm}$ ) [30].

According to Zauner et al. [31], the change of emissivity of steel surfaces due to the growth of an oxide layer reached a first maximum above $\varepsilon>0.8$ for an oxide film thickness of about $100 \mathrm{~nm}$. 
While the emissivity fluctuated in the beginning of the growth phase, it started to stabilize after reaching approximately $500 \mathrm{~nm}$ film thickness at a value of $\varepsilon=0.85$. These results were based on theoretical calculations. The fluctuations stem from interference phenomena of reflectance at oxide films at metallic surfaces which depended on oxide film thickness [31].

Del Campo et al. [32] studied the oxidation kinetics of iron below $570{ }^{\circ} \mathrm{C}$ and conducted emissivity measurements at four different temperatures: $415^{\circ} \mathrm{C}, 480{ }^{\circ} \mathrm{C}, 535^{\circ} \mathrm{C}, 570{ }^{\circ} \mathrm{C}$. Their results for thin oxide films were not contradicting to the afore mentioned. However, they had a stronger focus on various spectral wavelengths and on thicker oxide layers resulting from longer holding times.

\subsection{Calibration Approach of This Study}

The literature basis regarding emissivity determination and IR camera calibration for L-PBF is limited, also due to the requirement of specificity of each setup. Thus, this study aimed for the experimental temperature adjustment of an off-axis MWIR thermography setup, which was used for in situ thermal data acquisition of L-PBF processes in other studies of the authors [13,17]. The contact method was applied for this purpose. Furthermore, a correction of apparent emissivity values of the specific setup was pursued in in order to receive setup independent emissivity values of L-PBF bulk material and powder layers, which might be useful for, e.g., numerical simulations. A third goal of this work was the transferability of the technical equipment used during the calibration for the later use in other specific setups.

\section{Materials and Methods}

This section describes the experimental setup, the used equipment and materials, as well as the experimental variations.

\subsection{Thermographic Measurement Setup and L-PBF System}

A MWIR thermographic camera of type ImageIR8300 (InfraTec GmbH, Dresden, Germany) was mounted on top of a commercial L-PBF system of type SLM280HL (SLM Solutions Group AG, Lübeck, Germany). It had optical access to the build chamber through a purposely installed sapphire window in the ceiling of the chamber. The optical path was deflected by two gold mirrors to shift the observation field in the direction of the center of the build plate while keeping the angle of observation at approximately $0^{\circ}$ (angle between detector plane and build plate plane). Compared to similar off-axis IR camera setups used as thermal monitoring device in L-PBF (cf. Krauss et al. [33], Lane et al. [9]), the nearly perpendicular view onto the build plane is beneficial in terms of having a large focus area. Tilted systems are always faced with very limited areas which are in focus and usually have large defocused areas. A schematic and two photographs illustrate the setup in Figure 3. The same setup was also used in other work of the authors $[13,17]$ in the same configuration for in situ process monitoring means. The schematic also includes the heating device, which is described in Section 2.2. 


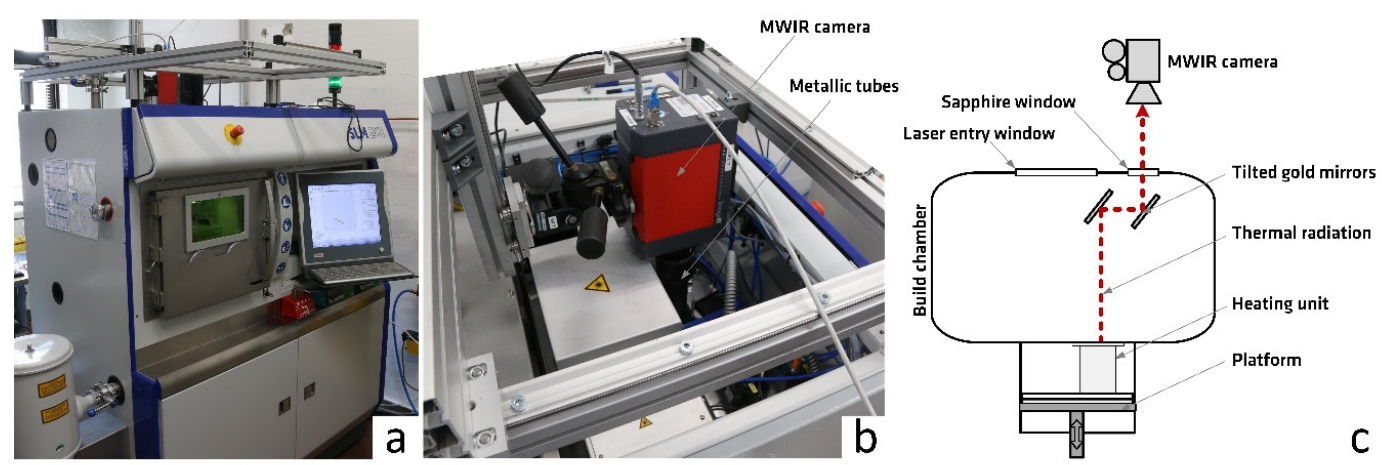

Figure 3. MWIR camera setup: installed camera on top of L-PBF machine ((a) side view, dimensions of the process chamber: $(280 \times 280 \times 360) \mathrm{mm}^{3}$; $(\mathbf{b})$ top view, dimensions of the camera body; $(244 \times 120 \times 160) \mathrm{mm}^{3} ;(\mathbf{c})$ schematic, not to scale).

The camera used a cooled InSb-focal-plane-array of size 640 pixel $\times 512$ pixel and a bit resolution of 14 bits was used. A $25 \mathrm{~mm}$ objective lens was used, resulting in a spatial resolution of the setup of approximately $420 \mu \mathrm{m}$ per pixel length. No additional external filters were used. The camera was sensitive in a spectral range from $2 \mu \mathrm{m}$ to $5.7 \mu \mathrm{m}$. The optical path outside of the build chamber was shielded by blackened metallic tubes, it could be interrupted manually by a shutter. According to the manufacturer's specifications, the reflectivity of the gold mirrors was above $99 \%$ in the spectral range of the camera, the transmissivity of the window above $83 \%$. Typical spectral reflectivity (mirrors), transmissivity (window, objective, camera internal filters) and sensitivity (camera detector) were known to be at least in the relevant spectral range between $2 \mu \mathrm{m}$ and $5.7 \mu \mathrm{m}$ and were used for the emissivity calculation in Section 3.3.

The camera was calibrated using a black body radiator by the manufacturer in different calibration ranges that could be chosen for the specific experiment. The following camera calibration ranges were used:

- 60-200: valid for black body temperature of $60{ }^{\circ} \mathrm{C}-200{ }^{\circ} \mathrm{C}$ (integration time: $89 \mu \mathrm{s}$ ),

- 200-400: valid for black body temperature of $200{ }^{\circ} \mathrm{C}-400{ }^{\circ} \mathrm{C}$ (integration time: $193 \mu$ s; internal attenuation filter A within the camera),

- 300-600: valid for black body calibration temperature $300{ }^{\circ} \mathrm{C}-600{ }^{\circ} \mathrm{C}$ (integration time: $45 \mu \mathrm{s}$; internal attenuation filter $\mathrm{B}$ within the camera).

Frame capturing of the camera was conducted at $100 \mathrm{~Hz}$. To reduce the amount of data, a subframe was used for capturing a size of 224 pixel $\times 160$ pixel, similar to the cited in situ measurements.

\subsection{Heated Reference Device}

A specimen was manufactured by L-PBF using 316L, which was used as the heated AM reference part. The manufacturing parameters were in accordance with the standard parameters used in [13] (laser power of $275 \mathrm{~W}$; scanning velocity of $700 \mathrm{~mm} / \mathrm{s}$; hatch distance of $0.12 \mathrm{~mm}$; layer thickness of $0.05 \mathrm{~mm}$; bi-directional scanning parallel to the edges of the specimen). No additional up-skin parameter was applied. The surface area roughness of the top surface was approximately Sa $=7 \mu \mathrm{m}$, determined at two areas of $0.8 \mathrm{~mm} \times 10 \mathrm{~mm}$ using a coherence scanning interferometry profilometer of the type Nexview (Zygo Corp., Middlefield, CT, USA). The cuboid specimen had the dimensions $13 \mathrm{~mm} \times 20 \mathrm{~mm} \times 140 \mathrm{~mm}$. In the middle of the upper surface of the specimen, a cross-like artefact with a depth of $0.5 \mathrm{~mm}$ was manufactured to help finding the focus level during the calibration experiments. The rim of the specimen was elevated by $0.5 \mathrm{~mm}$ at a width of $1 \mathrm{~mm}$.

A fixture was constructed that ensured the upright standing of the specimen, as well as thermal insulation between the specimen and the fixture by ceramic plates. A heating mat and a heating inverter of type ST11 (Sokol-Therm Deutschland GmbH, Eisenhüttenstadt, Germany) were used to heat up the specimen. The specimen was wrapped by the heating mat and placed within a sheet 
metal enclosure. For insulation reasons, an insulation wool was placed between the heating mat and the enclosure. To shield heat radiation towards the camera which did not come from the heated AM specimen, high-temperature fiberboard was used to cover the top of the heating device. Four K-type thermocouples (TC, TC1 to TC4) of $0.127 \mathrm{~mm}$ diameter were spot welded at the four sides of the specimen approximately $1 \mathrm{~mm}$ below the upper surface of the rim. At one side, an additional TC (TC Inv.) was installed to act as target measuring point for the heating inverter. The responses from the thermocouples were acquired through a measuring amplifier device of type MX1609 (HBM GmbH, Darmstadt, Germany) at a sampling rate of $10 \mathrm{~Hz}$. The heating device was positioned by lowering the build plate lift of the machine in such a way that the surface of the reference specimen was in the usual build plane of the L-PBF setup. A schematic of the specimen surface and the clamping are shown in Figure 4. This also includes the positioning of the thermocouples. Figure 5 shows photographs of the heating device. Two separate TCs were spot welded at the sheet metal and the substrate, respectively, in order to monitor the heat development at the device.

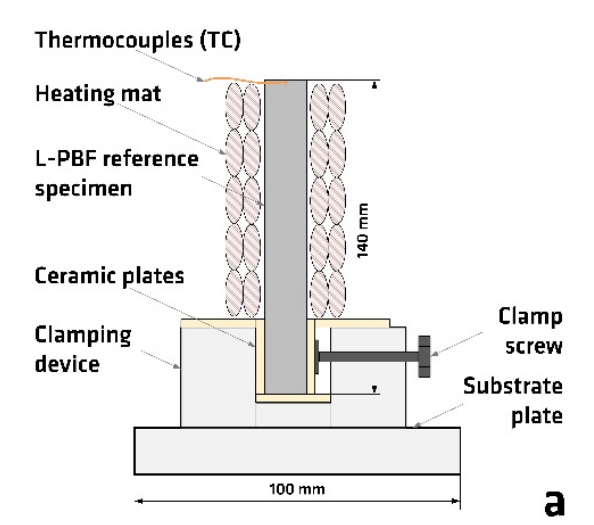

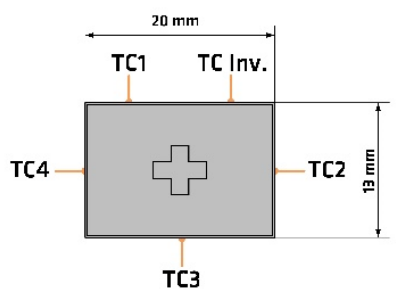

Top view on L-PBF reference specimen

Figure 4. (a) schematic of heating device without outer insulation; (b) schematic of specimen surface indicating TC positions. 

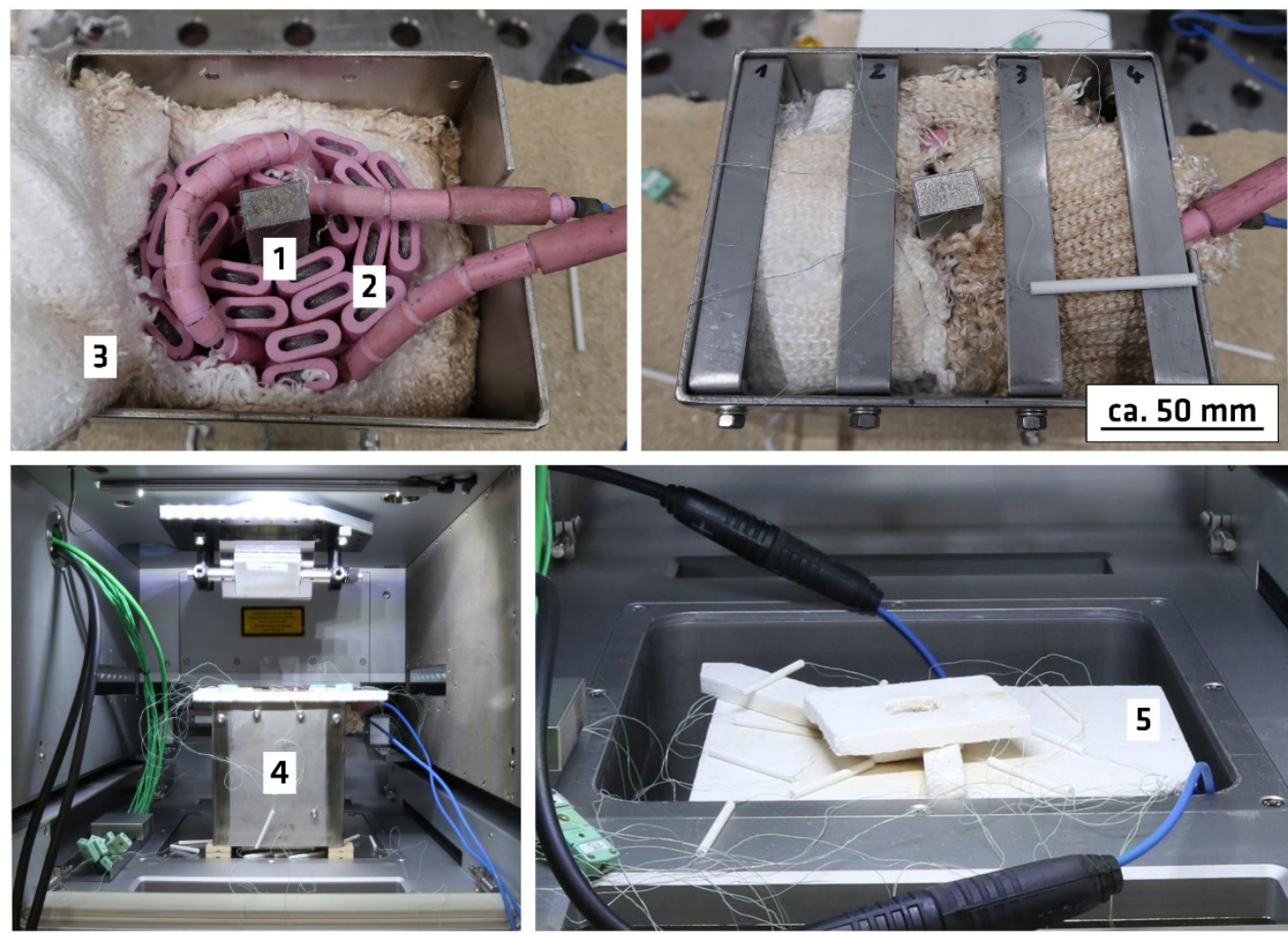

Figure 5. Photographs of mounted heating device: L-PBF reference specimen (1); heating mat (2); insulation wool (3); sheet metal enclosure (4); high-temperature fiberboard on top of the device (5); the heating device is placed at its measuring position (position 1, as described in Section 2.4.3).

\subsection{Examination Methodology}

Recording of MWIR camera data and TC data was started synchronously by the experimental conductors at different times during the heating cycle. The apparent temperature data of the MWIR camera were gained by using the software IRBIS3 professional (InfraTech GmbH, Dresden, Germany). Four regions of interest (ROIs) were defined across the top surface of the specimen, excluding the cross in the middle of the surface as well as the rim in order to exclude additional surface property effects, cf. Figure 6. The mean temperatures of these four ROIs were exported as ASCII files. Subsequent analysis was conducted using the software Origin 2019 (OriginLab Corporation, Northampton, MA, USA). The total mean of all pixels within the four ROIs was taken as apparent temperature value of the camera. Considerations of standard deviations and fluctuations are discussed in Section 3.5. The TC temperature data were also analyzed using Origin 2019.

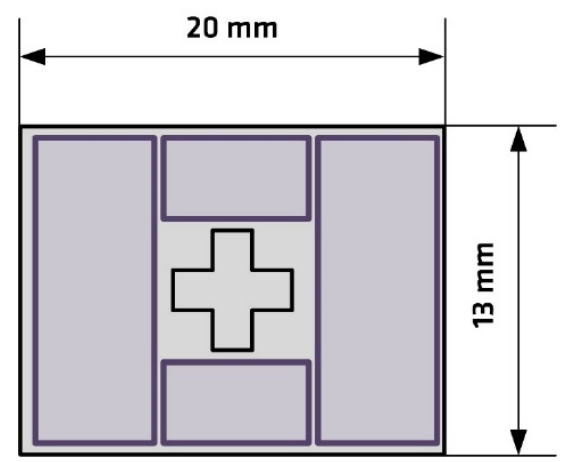

Figure 6. Schematic of the ROIs (purple color) for data capture. 


\subsection{Experimental Measurment Variations}

The temperature calibration experiments were conducted at different conditions, which are introduced in this section. Unless stated otherwise, all experiments were conducted under typical L-PBF working conditions. Thus, the experiments were conducted inside the build chamber and under argon gas atmosphere at a gas flow velocity of approximately $21.5 \mathrm{~m} / \mathrm{s}$ (measuring sensor in the gas circulation pipes), with a gas flow flushing the chamber from the right to the left. A one-point nonuniformity correction (NUC) was always conducted before the beginning of any new capturing of the MWIR camera. This was done by placing a shutter in the optical path outside of the build chamber and using the NUC function of the camera. The optical shutter was at room temperature. A manual refocusing of the objective lens was conducted whenever a blackbody calibration range of the camera was changed. This was necessary, since the additional camera internal filters A and B in the calibration ranges 200-400 and 300-600 changed the optical path length.

The following experimental variations were investigated using different camera calibration ranges:

- $\quad 316 \mathrm{~L}$ L-PBF surface at temperatures between $100{ }^{\circ} \mathrm{C}$ and $700{ }^{\circ} \mathrm{C}$,

- $\quad 316 \mathrm{~L}$ powder layer at temperatures between $100{ }^{\circ} \mathrm{C}$ and $650{ }^{\circ} \mathrm{C}$,

- IN718 powder layer at temperatures between $100{ }^{\circ} \mathrm{C}$ and $650{ }^{\circ} \mathrm{C}$, and

- $\quad 316 \mathrm{~L}$ oxidized L-PBF surface at three different positions.

The individual experiments are explained in detail in the respective sections.

\subsubsection{Temperature Variations at a Non-Oxidized L-PBF Surface (316L)}

During the temperature variation experiments, the virgin 316L L-PBF specimen was heated up to a temperature of $750^{\circ} \mathrm{C}$ in several stages in the L-PBF build chamber. Data couples of TC temperatures and apparent temperatures were acquired. The heat up was paused at different temperature stages to reach temperature plateaus. Different camera calibration ranges were used during the data acquisition (see Section 2.1). The sheet metal enclosure of the heating device reached a maximum temperature of approximately $350^{\circ} \mathrm{C}$ and the substrate of the fixture a maximum temperature of approximately $375{ }^{\circ} \mathrm{C}$ during the heating experiments. All temperatures measured by the temperature sensors of the L-PBF system stayed within the narrow rage of the specifications of the manufacturer during the experiments, e.g., the build chamber temperature was between $31^{\circ} \mathrm{C}$ and $36^{\circ} \mathrm{C}$.

\subsubsection{Temperature Variations at Powder Surface (316L and IN718)}

Two different powder materials were spread on top of the specimen in two separate experiments before the heating up. The powder was manually placed using a spatula in the middle of the top surface of the specimen and then spread manually over its entire surface by using a razor blade. Thereby, a powder bed of approximately $500 \mu \mathrm{m}$ thickness was generated according to the dimensions of the rim. Table 1 contains information of the powder properties according to supplier's information (SLM Solutions Group AG, Lübeck, Germany). The heating device with the powder bed on top was heated up to $650{ }^{\circ} \mathrm{C}$ in several stages.

Table 1. Powder properties according to supplier's information.

\begin{tabular}{ccc}
\hline Powder Properties & $\begin{array}{c}\text { Powder 1 } \\
\text { AISI 316L (1.4404) }\end{array}$ & $\begin{array}{c}\text { Powder 2 } \\
\text { Inconel 718 }\end{array}$ \\
\hline $\mathrm{D}_{10}$ in $\mu \mathrm{m}$ & 18.22 & 25.50 \\
\hline $\mathrm{D}_{50}$ in $\mu \mathrm{m}$ & 30.50 & 37.60 \\
\hline $\mathrm{D}_{90}$ in $\mu \mathrm{m}$ & 55.87 & 57.07 \\
\hline Mean diameter in $\mu \mathrm{m}$ & 34.69 & 39.49 \\
\hline Apparent density in $\mathrm{g} / \mathrm{cm}^{3}$ & 4.58 & 4.56 \\
\hline
\end{tabular}




\subsubsection{Positioning}

To evaluate a potential influence of the $x-y$ position of the target object within the build chamber, measurements were conducted at three different positions as illustrated in Figure 7. The heating device was placed manually. The measurements were carried out at a specimen surface temperature of around $400{ }^{\circ} \mathrm{C}$. The center of the specimen was approximately located at the following coordinates (reference 0 as in Figure 7, coordinates in mm): x140, y66 (Position 1); x113, y81 (Position 2); x143, y140 (Position 3). Position 1 and position 2 are approximately at the positions where two of the in situ monitored specimens of $[13,17]$ were located. Position 3 was representative of a specimen in the center of the L-PBF substrate plate. The tilt of the gold mirrors as well as the focus of the camera had to be adjusted to capture position 3. Position 1 and position 2 were located within the same chosen field of view. These measurements were conducted using an oxidized specimen, which was oxidized in pre-tests of the heating device up to a temperature of $600^{\circ} \mathrm{C}$ outside of the L-PBF machine at ambient atmosphere beforehand. Apart from the position shifts described here, all other experiments were conducted at approximately position 1 .

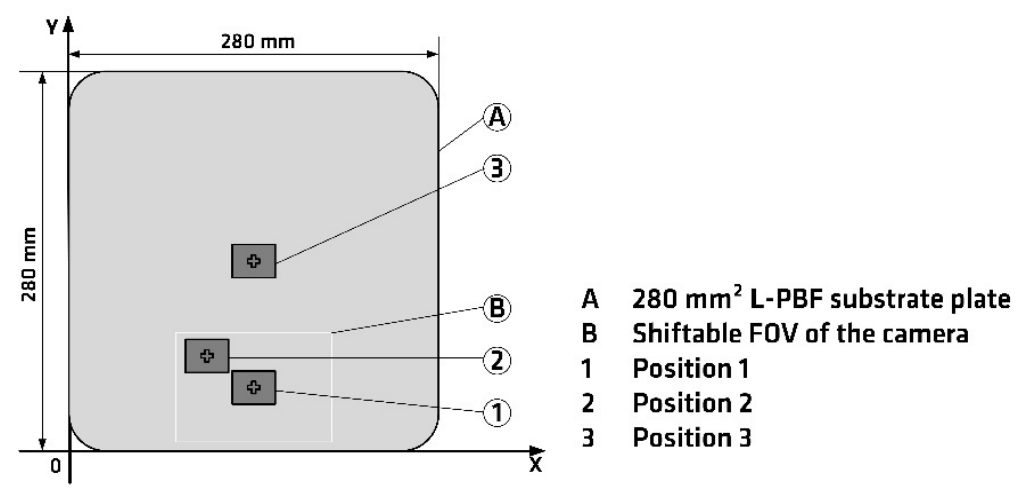

Figure 7. Positioning of the heated specimen on top of the (lowered) build plate.

\subsection{Determination of Emissivity Values}

Two different ways of determining emissivity values were implemented, resulting in non-corrected, so-called apparent emissivity values and corrected, closer-to-real emissivity values. The values were calculated for the distinct measurement points, which comprised the temperature of the thermocouples $T_{T C}$, the apparent temperature of the MWIR camera $T_{a p p}$, and the temperature in the build chamber $T_{0}$.

\subsubsection{Determination of Apparent Emissivity Values}

The computation of emissivity values without consideration of transmission losses and thermal stray radiation leads to the so-called apparent emissivity $\varepsilon_{a p p}$. The apparent emissivity $\varepsilon_{a p p}$ can be computed using Equation (3) (neglecting the wavelength dependency, grey body approximation). Thereby, an integration of Equation (1) (Planck's law) in the spectral range of the MWIR camera $\left(\lambda_{1}=2 \mu \mathrm{m}\right.$ to $\left.\lambda_{2}=5.7 \mu \mathrm{m}\right)$ for the reference TC temperature $\left(W_{\lambda b}\right)$ and for the apparent temperature of the camera of the respective calibration range $\left(W_{\lambda r}\right)$ must be conducted:

$$
\varepsilon_{\lambda}\left(T=T_{T C}\right)=\frac{\int_{\lambda_{2}}^{\lambda_{1}} W_{\lambda r}\left(\lambda, T_{a p p}\right) d \lambda}{\int_{\lambda_{2}}^{\lambda_{1}} W_{\lambda b}\left(\lambda, T_{T C}\right) d \lambda}
$$

This simplified analysis was performed, since it is a widely used way to estimate emissivity values.

\subsubsection{Determination of Corrected Emissivity Values}

The calculation of the apparent emissivity by Equation (4) is a rough estimate. This analysis neglects the radiation that was reflected from the surroundings at the surface as well as all the spectral 
characteristics of all optical elements and the camera detector. Assuming a homogeneous thermal background radiation of a black body at temperature $T_{0}$, the emitted spectral radiosity of a grey body is:

$$
W_{\lambda r}\left(\lambda, T, \varepsilon, T_{0}\right)=\varepsilon(T) \cdot W_{\lambda b}(\lambda, T)+(1-\varepsilon(T)) \cdot W_{\lambda b}\left(\lambda, T_{0}\right)
$$

Here, the spectral and angular dependence of $\varepsilon$ are still neglected; thus, the determined values are still effective values for the spectral range of the camera. To better estimate the surface emissivity, first, the total irradiance measured by the camera during calibration at a black body was calculated, considering the spectral transmissivity of the optics present during the calibration $\tau_{\text {opt,cal }}(\lambda)$ and the spectral responsivity of the detector $S(\lambda)$ :

$$
E_{c a l}(T)=\int_{-\infty}^{\infty} W_{\lambda b}(\lambda, T) \cdot \tau_{o p t, c a l}(\lambda) \cdot S(\lambda) \cdot d \lambda
$$

Please note that the influence of the atmosphere (absorption and emission) is neglected here as well. Knowing the needed optical properties (at least typical values), $E_{c a l}\left(T_{\text {app }}\right)$ can be calculated for all measured apparent temperatures $T_{a p p}$, using Equation (6). Then, in a next step, the radiance of the surface that was measured during the experiment by the camera can be calculated as follows:

$$
E_{\text {meas }}\left(T, \varepsilon, T_{0}\right)=\int_{-\infty}^{\infty} W_{\lambda r}\left(\lambda, T, \varepsilon, T_{0}\right) \cdot \tau_{\text {opt, meas }}(\lambda) \cdot S(\lambda) \cdot d \lambda
$$

For each measurement point above, the temperature of the inner ceiling of the build chamber was monitored by the L-PBF system's sensors. This temperature was used as surroundings temperature $T_{0}$ here. Please note that the experimental transmissivity $\tau_{\text {opt,meas }}(\lambda)$ was dependent on the selected calibration range of the camera, since the camera internal absorptive filters differed.

As the camera outputs the same values at the same irradiance rather than at the same temperature of the object observed by the camera, the emissivity can be reconstructed by setting:

$$
E_{\text {cal }}\left(T_{\text {app }}\right)=E_{\text {meas }}\left(T_{T C}, \varepsilon, T_{0}\right)
$$

for each measurement point $\left(T_{T C}, T_{a p p}, T_{0}\right)$, where $\varepsilon$ was the only unknown variable. Thus, $\varepsilon_{c o r r}$ was determined by:

$$
\varepsilon_{\text {corr }}=\underset{0<\varepsilon<1}{\arg \min }\left|E_{\text {meas }}\left(T_{T C}, \varepsilon, T_{0}\right)-E_{\text {cal }}\left(T_{\text {app }}\right)\right|
$$

\section{Results and Discussion}

\subsection{Selection of Thermocouples}

The TCs showed temperature deviations depending on their position with respect to the sample surface and the gas flow, as shown in Figure 4. Figure 8 shows exemplarily a sequence of TC measurements during a cooling down phase of the specimen. While deviations of the measured temperature were small between TC1, TC 3 and TC4, the temperature measured at TC 2 was remarkably lower than at the other TCs. TC2 was directly placed in the gas flow. This deviation could be associated with the gas flow, as the difference decreased when reducing the gas flow velocity at the times of $103.5 \mathrm{~s}(21.5 \mathrm{~m} / \mathrm{s}$ before $103.5 \mathrm{~s}$ ), $217 \mathrm{~s}$ (reduction to $14.9 \mathrm{~m} / \mathrm{s}$ until $217 \mathrm{~s}$ ), $330 \mathrm{~s}$ (reduction to $8.9 \mathrm{~m} / \mathrm{s}$ until $330 \mathrm{~s}$ ) and $344 \mathrm{~s}$ (reduction to $0 \mathrm{~m} / \mathrm{s}$ until $344 \mathrm{~s}$, no gas flow after $344 \mathrm{~s}$ ) in the presented example. Thus, TC2 values were excluded from further examinations. The mean of TC1, TC3 and TC4 was taken as surface reference temperature in all subsequent considerations. A constant surface temperature was assumed. A consideration of measurement uncertainty is given in Section 3.5. 


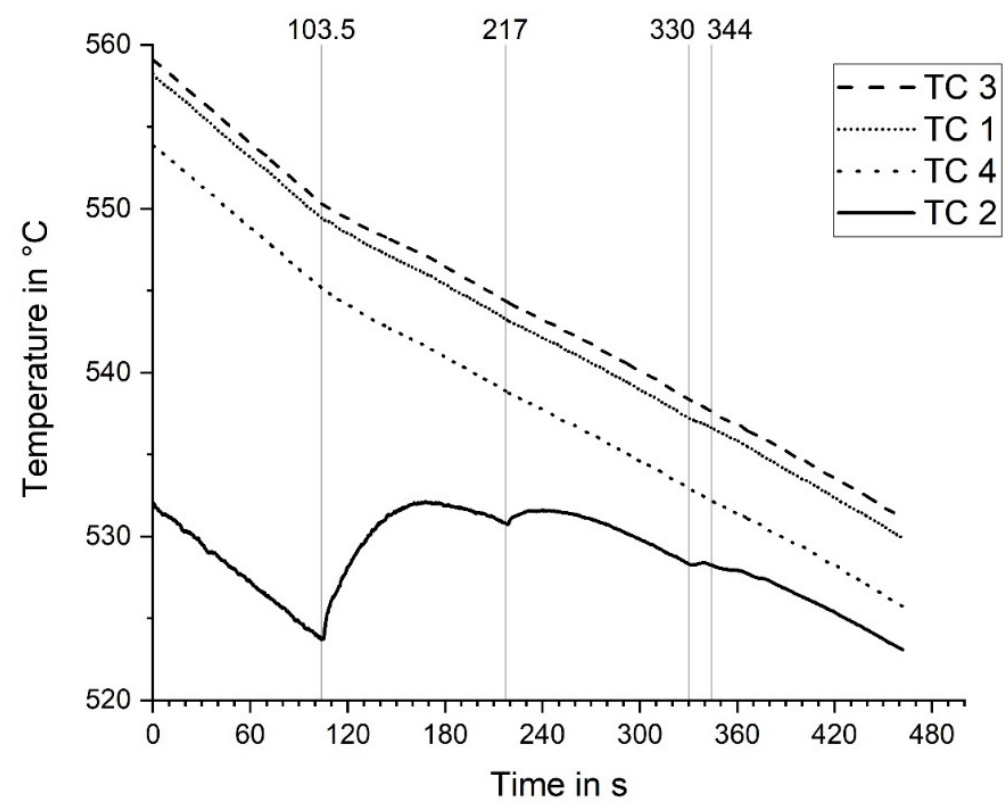

Figure 8. Effect of gas flow on TC temperature. The gas flow velocity decreases at the highlighted times.

\subsection{Apparent Emissivity}

The apparent emissivity values are presented in the following subsections for the 316L L-PBF surface, the 316L powder layer and the IN718 powder layer.

\subsubsection{Apparent Emissivity of the 316L L-PBF Surface}

The comparison of the reference temperature values of the 316L L-PBF surface, the mean value of three TCs (see Section 3.1), and the respective apparent temperature values, calculated as the mean apparent temperature of the four ROIs (see Section 2.3) of the MWIR camera data, clearly indicated that the apparent temperature values of the black body calibrated MWIR camera underestimated the reference temperatures. The difference between reference temperature and apparent temperature increased from approximately $64^{\circ} \mathrm{C}$ to $181{ }^{\circ} \mathrm{C}$ at reference temperatures of approximately $134{ }^{\circ} \mathrm{C}$ and $579{ }^{\circ} \mathrm{C}$, respectively. This underestimation was not surprising, as the emissivity of the real L-PBF surface was expected to be much smaller than unity, which was assumed by the apparent temperature computation of the camera. Figure 9 displays data couples of TC reference temperatures and apparent temperatures of the MWIR camera (black hollow symbols). Three different calibration ranges of the camera were used to measure the large variance of surface temperatures during the experiment (see Section 2.1). The measured data for each calibration range are distinguished by the distinct symbols (circle, square, triangle) in the plot. The connected data points of the calibration ranges 60-200 and 200-400 follow a linear trend, whereas a non-linear trend is revealed for the calibration range 300-600. In addition, steps between the curves of the distinct calibration ranges are noticeable. Both are discussed in the course of the emissivity determination, below. 


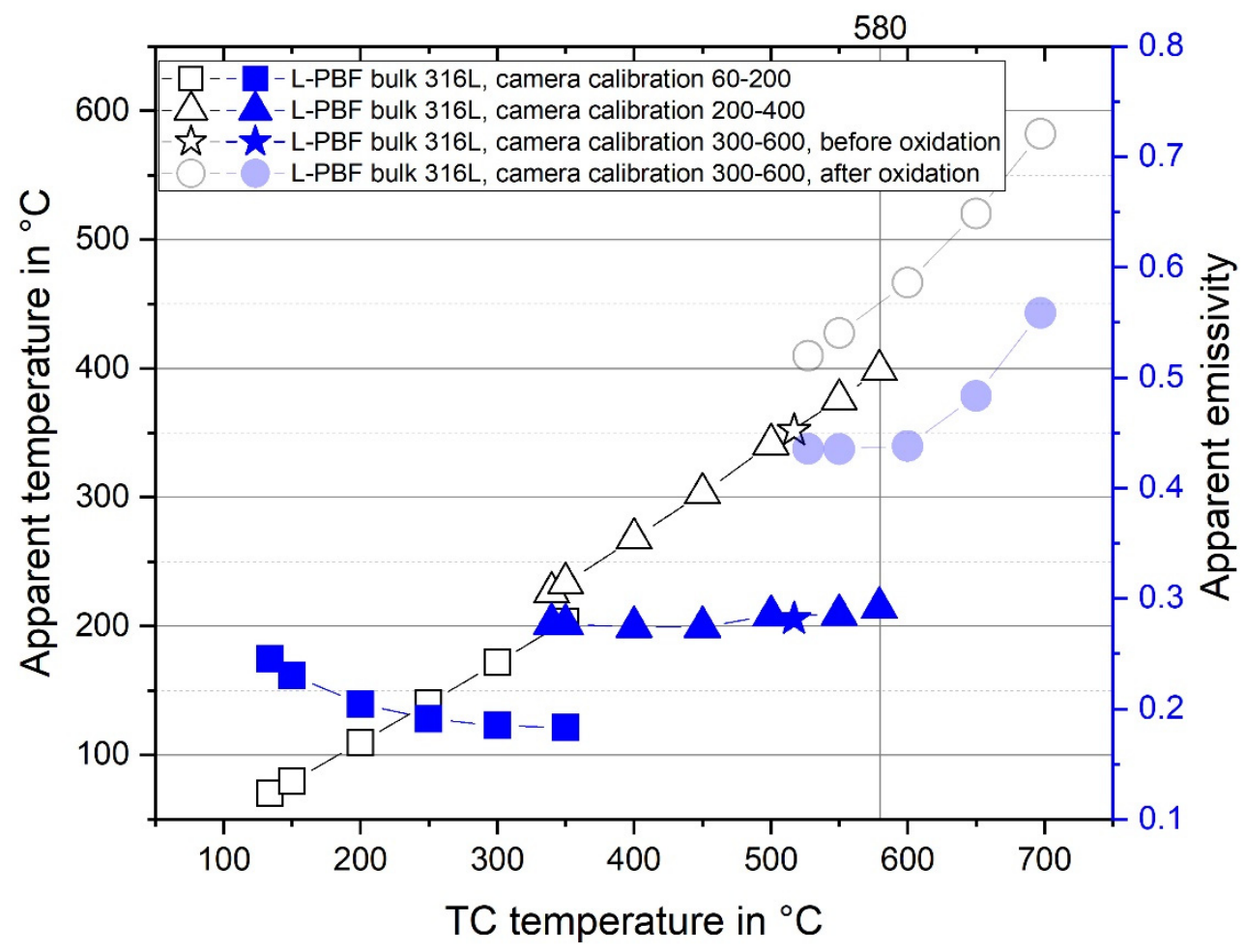

Figure 9. Apparent temperature (black hollow symbols) and apparent emissivity (blue full symbols) of 316L L-PBF bulk surface over measured TC temperature. In the camera calibration range 300-600, measurements were conducted before the onset of increased oxidation (star symbols) and after oxidation (circle symbols).

The apparent emissivity $\varepsilon_{a p p}$ of the $316 \mathrm{~L}$ L-PBF surface was computed using Equation (4) (neglecting the wavelength dependency, grey body approximation) for all data couples presented in Figure 9 (reference temperatures between $134{ }^{\circ} \mathrm{C}$ and $700{ }^{\circ} \mathrm{C}$ ). In addition to the temperature data couples (black hollow symbols), Figure 9 displays the respective apparent emissivity $\varepsilon_{a p p}$ (blue full symbols).

The apparent emissivity $\varepsilon_{a p p}$ of the surface of the L-PBF specimen in the particular setup showed a decrease in the camera calibration range 60-200 with increasing temperature, starting at $\varepsilon_{a p p}=0.25$ at a temperature of $134{ }^{\circ} \mathrm{C}$, leveling off to $\varepsilon_{a p p}=0.18$ at temperatures above $300{ }^{\circ} \mathrm{C}$. However, the radiation of the ambient temperature was not considered for this calculation of the apparent emissivity. Especially for lower temperatures, which were of a similar magnitude as the ambient temperature, the radiation of ambient temperature is expected to lead to significant falsifications if not considered. A correction analysis including data of measured ambient temperatures of the build chamber of around $33^{\circ} \mathrm{C}$ is presented in Section 3.3.

When switching the calibration range from 60-200 to 200-400 at constant TC temperature, there was a jump in the apparent temperature of more than $25 \mathrm{~K}$. This led to an increased apparent emissivity of the surface of the L-PBF specimen of approximately $\varepsilon_{a p p}=0.28$ at temperatures between $350^{\circ} \mathrm{C}$ and $580^{\circ} \mathrm{C}$. To examine this peculiar effect, additional experiments were conducted outside of the L-PBF setup: Firstly, experiments were performed using a black body radiator (Fluke 4181, Fluke Corporation, Norwich, UK) set to a temperature of $200{ }^{\circ} \mathrm{C}$. Changes of the camera calibration range between 60-200 and 200-400 showed only a small deviation of the measured temperature by the camera of below $1 \mathrm{~K}$, indicating a correct black body calibration. Secondly, further investigations using 316L samples produced in the described L-PBF machine, heated on a hot plate to $200{ }^{\circ} \mathrm{C}$ were conducted. Here, the jump in the apparent temperature observed in the calibration experiment at the L-PBF setup was reproduced. Thus, this effect was in fact caused by the non-unity emissivity of the material. A consultation of the camera manufacturer revealed that the absorptive filter elements that were introduced to the optical path within the camera in the calibration ranges at elevated 
temperatures (200-400, 300-600) have a transmissivity that strongly depends on the wavelength. Therefore, their spectral transmissivity had to be considered for a correct emissivity determination and correction. A further analysis is presented in Section 3.3. The big step between the apparent emissivity values of distinct calibration ranges obtained by the simple analysis approach can be seen as an imposing example of the risk of data misinterpretation when using commercial thermography cameras with various calibration ranges. Unless clearly stated by the vendor, one has to be very careful when transferring experimentally determined values to slightly other conditions of the setup, in this case to another camera calibration range.

\subsubsection{Oxidation Effects on the Apparent Emissivity of the 316L L-PBF Surface}

At TC temperatures above approximately $500{ }^{\circ} \mathrm{C}$, tempering colors could be recognized by the human eye, beginning with a slightly brownish appearance, which darkened until approximately $580{ }^{\circ} \mathrm{C}$ and then turned into a bluish appearance, inspected through the green UV protection window of the process chamber door. Thus, despite the low oxygen content in the build chamber during the experiments, oxidation of the heated surface was still occurring. Oxidation layers can drastically change emissivity values. This effect is well known in the literature [20], and an excursus into this matter is therefore given in the introduction Section 1.4.

Such an oxidation-driven change of emissivity values was clearly revealed at temperatures above $580{ }^{\circ} \mathrm{C}$ (compare Figure 9). Additionally, a slight increase in apparent emissivity could be seen for temperatures above $500{ }^{\circ} \mathrm{C}$ (increase from 0.28 to 0.29 ), which might be attributed to the onset of oxidation as visually noticed during the heat up. While the apparent emissivity change between $500{ }^{\circ} \mathrm{C}$ and $580{ }^{\circ} \mathrm{C}$ was very small, the emissivity values changed drastically above $580{ }^{\circ} \mathrm{C}$. The oxidation of the surface got too strong to present reliable emissivity values of an unoxidized or only slightly oxidized $316 \mathrm{~L} \mathrm{L-PBF}$ surface above $580^{\circ} \mathrm{C}$. The measurement data which are displayed transparent in Figure 9 and their respective computations of emissivity values were heavily influenced by a change of emissivity due to oxidation. This was in good agreement with the visually noticeable tempering colors and the literature review. For example, apparent emissivity values of 0.58 were determined using the same camera in the laser metal deposition of AISI 316L, where stronger oxidation is expected to occur due to a less efficient shielding of oxygen by a local shielding gas flow in surrounding air conditions [34].

Remarkably, there are measurement points between $500{ }^{\circ} \mathrm{C}$ and $580{ }^{\circ} \mathrm{C} \mathrm{TC}$ temperature, which were obtained at different times and different camera calibration ranges, i.e., calibration ranges 200-400 and 300-600, showing huge differences in apparent emissivity for the same temperatures. The measurement of the data points symbolized by full circles (calibration range 300-600) was conducted approximately $70 \mathrm{~min}$ after the measurement series symbolized by triangles (calibration range 200-400). The temperature of the specimen in between these two measurement series was constantly higher than $530{ }^{\circ} \mathrm{C}$, most of the time around $600{ }^{\circ} \mathrm{C}$. Apparently, the oxidation layer thickness was still very small during the measurements in the calibration range 200-400, but had enough time and temperature to grow before the measurements at a calibration range of 300-600 were conducted. This would explain the discrepancy between apparent emissivity for the same TC temperatures. Interestingly, the apparent emissivity step in Figure 9 between the calibration ranges 200-400 and 300-600 can be explained by oxidation without further correction for the change of the internal filter of the camera: The measurement of the extra dot (star symbol) was taken using the calibration range 300-600 during the measurement series represented by triangles (200-400), and thus before the strong oxidation started. It shows a very similar apparent emissivity to the results obtained in the 200-400 calibration range. This observation might be explained by a similar spectral dependence of the transmissivity of filter A and B (at lower amplitudes for filter B). This is important to know, for any later use of these calibration ranges, which were identified as most relevant for in situ L-PBF monitoring means (cf. [13]). 


\subsubsection{Apparent Emissivity of the 316L Powder Layer}

The determination of the apparent emissivity and the comparison of TC reference temperatures and thermographically acquired apparent temperatures of the 316L powder layer followed the same procedure as for the solid 316L L-PBF surface, described and discussed in the previous section. Figure 10 displays the respective temperature data couples and computed apparent emissivity values of the 316L powder for the three different camera calibration ranges. For comparison reasons, it also contains the respective values of the L-PBF 316L surface at similar conditions in transparent colors.

The non-corrected emissivity values of the powder layer leveled to approximately $\varepsilon_{a p p}=0.33$ in the camera calibration range $60-200$. Before the onset of increased oxidation above $580{ }^{\circ} \mathrm{C}$, apparent emissivity was calculated to approximately $\varepsilon_{a p p}=0.43$ for the camera calibration ranges 200-400 and 300-600. In comparison to the solid L-PBF surface of the same material, the 316L powder layer showed significantly increased emissivity values. This was already mentioned in the literature, e.g., in [14], and originates from the strongly increased surface roughness of a powder layer compared to a solid L-PBF surface. It also explains the potential occurrence of apparent temperatures of new recoated powder layers which could be higher than the apparent temperatures at the same position prior to recoating in L-PBF real manufacturing, monitored by in situ thermography, as in [17].

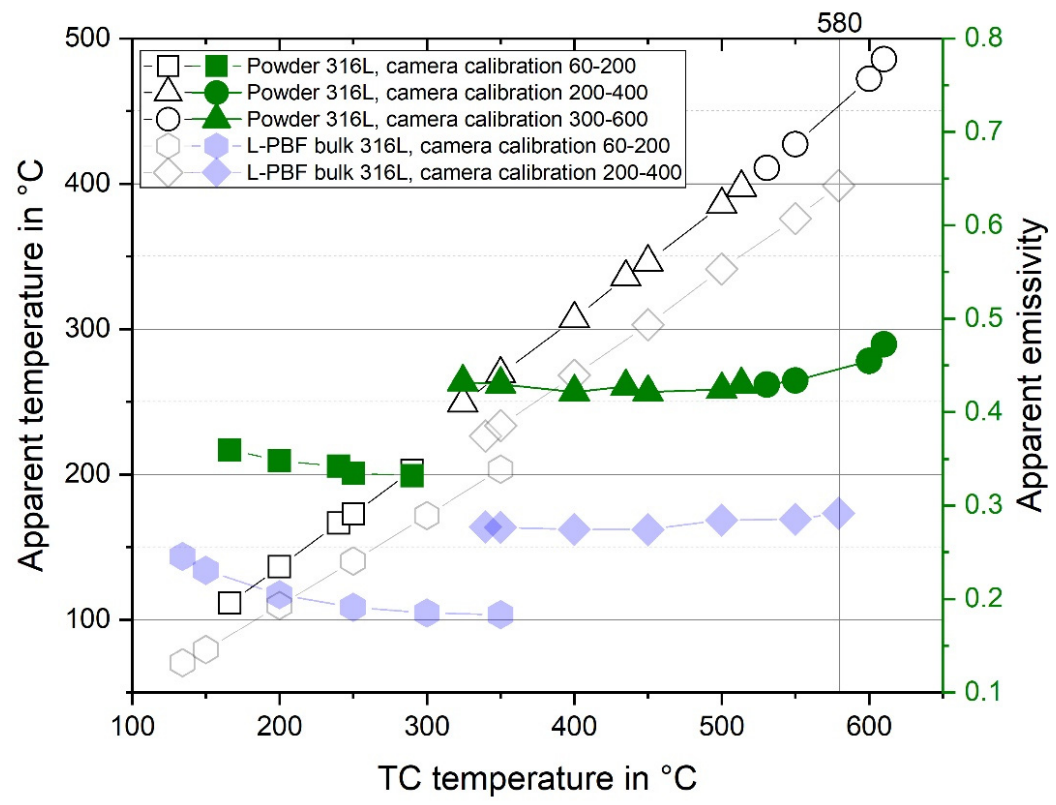

Figure 10. Apparent temperature (black hollow symbols) and apparent emissivity (green full symbols) of the 316L powder layer over measured TC temperature. For comparison, apparent temperature (gray hollow symbols) and apparent emissivity (blue full symbols) of the 316L L-PBF bulk surface over TC temperature are also depicted.

\subsubsection{Apparent Emissivity of the IN718 Powder Layer}

The determination of the apparent emissivity and the comparison of TC reference temperatures and thermographically acquired apparent temperatures of the IN718 powder layer followed the same procedure as for the 316L L-PBF surface, described and discussed in Section 3.2.1. The results are plotted in Figure 11. The non-corrected emissivity values of the IN718 powder layer leveled to approximately $\varepsilon_{a p p}=0.34$ in the camera calibration range 60-200. The apparent emissivity was calculated to approximately $\varepsilon_{a p p}=0.41$ to 0.42 for the camera calibration ranges 200-400 and 300-600. The determined apparent emissivity values of the IN718 powder layer were at a similar level as the values of the 316L powder layer, depicted in Figure 12. In contrast to the 316L powder, the rise of apparent emissivity values above $580^{\circ} \mathrm{C}$ is significantly smaller, which is assumed to be attributed to other oxidation kinetics for the nickel-based IN718 as compared to the stainless steel 316L. This is in 
good agreement with experiments by del Campo et al. [35], who showed a rather small influence of short-term oxidation at $700^{\circ} \mathrm{C}$ of IN718 on emissivity.

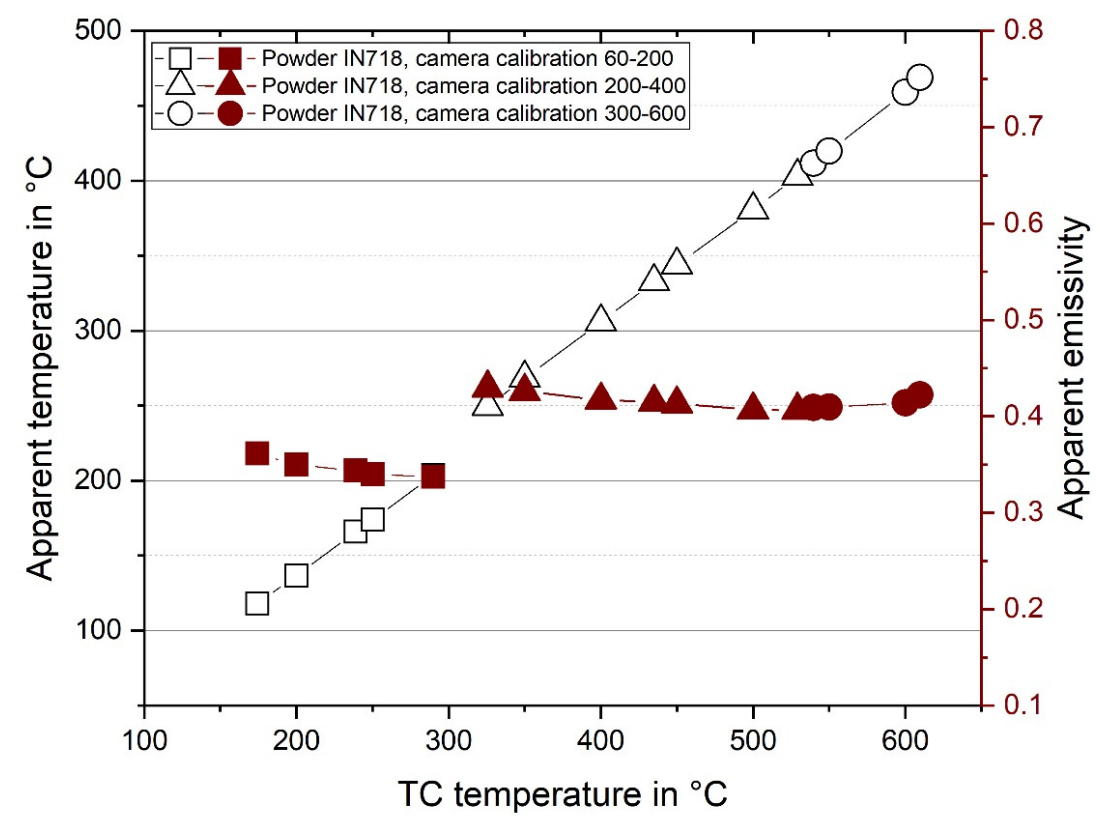

Figure 11. Apparent temperature (black hollow symbols) and apparent emissivity (brown full symbols) of IN718 powder layer over measured TC temperature.

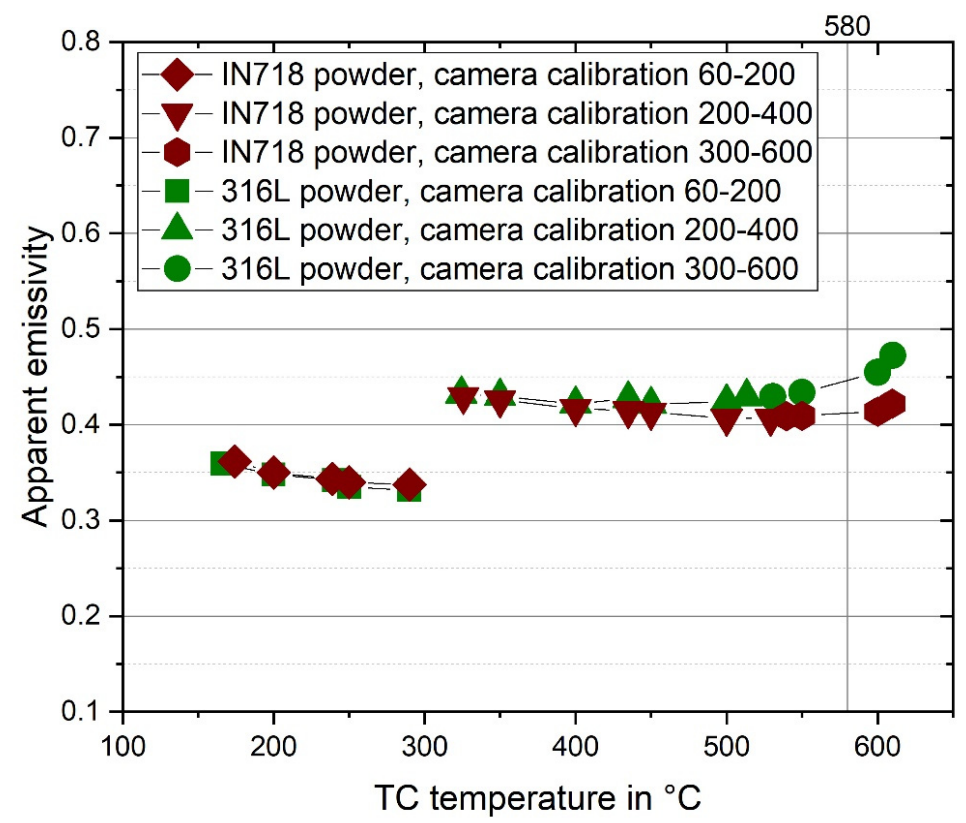

Figure 12. Comparison of apparent emissivity results of IN718 powder layer (brown full symbols) and 316L powder layer (green symbols) over measured TC temperature.

\subsection{Determination of Corrected Emissivity}

The corrected emissivity values $\varepsilon_{\text {corr }}$ are presented in the following subsections for the 316L L-PBF surface, the 316L powder layer and the IN718 powder layer. The correction analysis is described in Section 2.5.2. 


\subsubsection{Corrected Emissivity of 316L L-PBF Surface}

When considering the radiation that was reflected from the surroundings at the surface as well as all the spectral characteristics of the optical elements including the different internal filters as described above, some fundamental changes of the corrected emissivity curves compared to the apparent emissivity curves (discussed in Section 3.2.1) can be observed. Figure 13 compares the corrected emissivity values with the non-corrected apparent emissivity values. The following discussion focuses on the emissivity values of the non-oxidized surface, i.e., below $580{ }^{\circ} \mathrm{C}$.

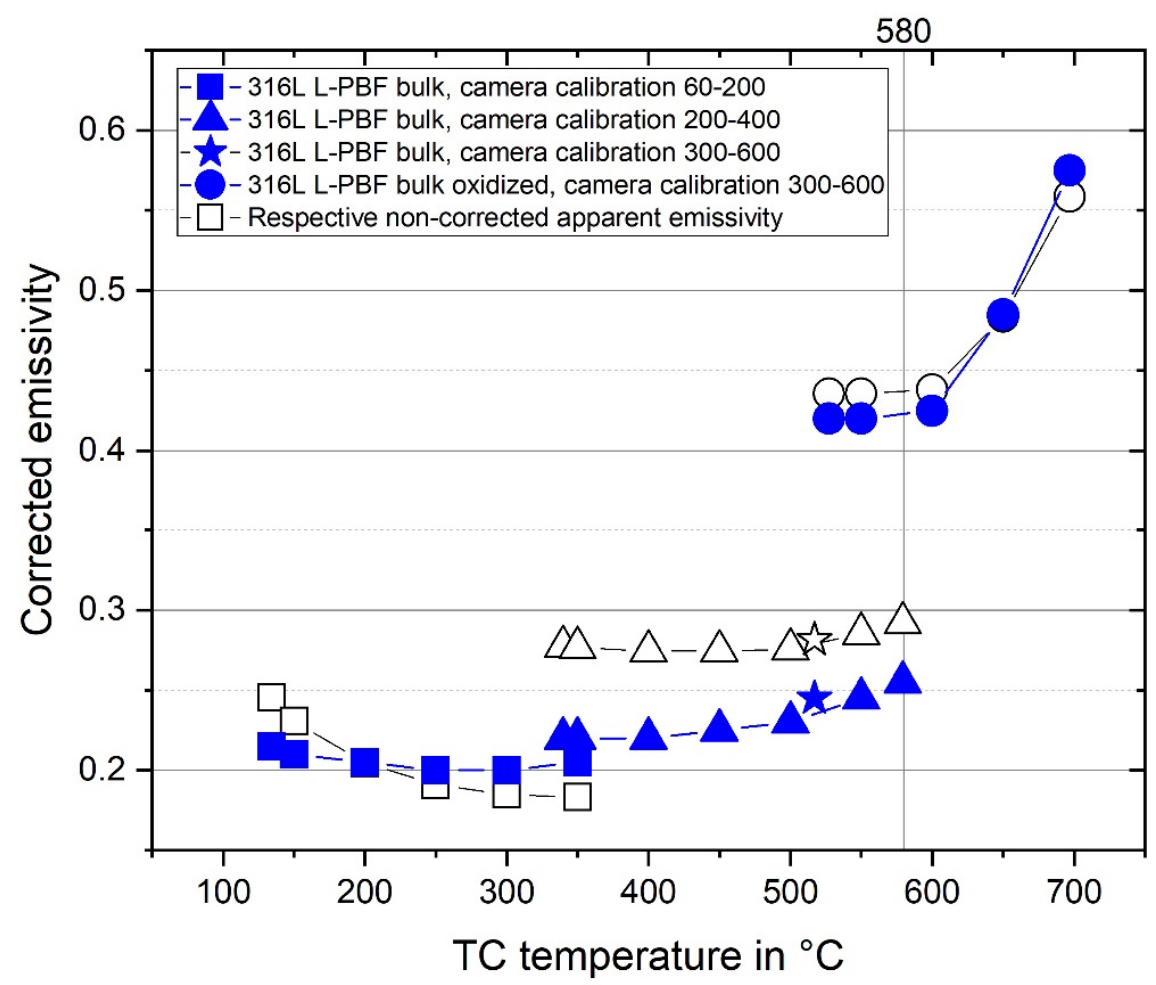

Figure 13. Comparison of corrected (blue symbols) and non-corrected apparent (black hollow symbols) emissivity values of 316L L-PBF bulk surface over measured TC temperatures.

First of all, the significant effect of apparently increasing emissivity values in the lower temperature region decreased drastically. The radiation of the surroundings (build chamber temperature around $33^{\circ} \mathrm{C}$ ) had a strong influence at relatively low temperatures of the target object, which resulted in the apparent increase of the non-corrected emissivity values with decreasing TC temperatures. Therefore, the corrective analysis flattened the curve in this region. However, there is still a slight increase below a TC temperature of $250{ }^{\circ} \mathrm{C}$. This was assumed to be a result of the position of the TC of the L-PBF system within the build chamber, which was located toward the front of the chamber ceiling, rather than close to the optical path of the IR camera. As a result of the TC position, a slight underestimation of the radiation of the surroundings $T_{0}$ could be assumed to be responsible for this, as, e.g., a value of $T_{0}=38{ }^{\circ} \mathrm{C}$ leads to a complete flattening of the curve.

Secondly, the huge jump of the apparent emissivity values connected to the change of the calibration range of the camera from 60-200 to 200-400 almost disappeared by the correction analysis as a result of the consideration of the distinct spectral transmissivities of the respective internal filters, which changed with the changing calibration ranges. The small remaining jump between the real emissivity values of the different calibration ranges is assumed to be attributed to possible slightly differing optical parameters of the actual optical elements from the typical values used for the calculations (see Section 3.5). 
It was revealed that the emissivity of the L-PBF bulk surface used in this experimental setup increased with increasing temperatures. The computed emissivity of 316L L-PBF bulk surface varied between $\varepsilon_{\text {corr }}=0.2$ and $\varepsilon_{\text {corr }}=0.23$ in the temperature region from $200{ }^{\circ} \mathrm{C}$ to $500{ }^{\circ} \mathrm{C}$ and between $\varepsilon_{\text {corr }}$ $=0.23$ and $\varepsilon_{\text {corr }}=0.25$ in the temperature region between $500{ }^{\circ} \mathrm{C}$ and $580{ }^{\circ} \mathrm{C}$, where slight oxidation effects could not be excluded, as discussed in Section 3.2.1. These values are in good agreement with literature values of stainless steel [36], as presented in Figure 14.

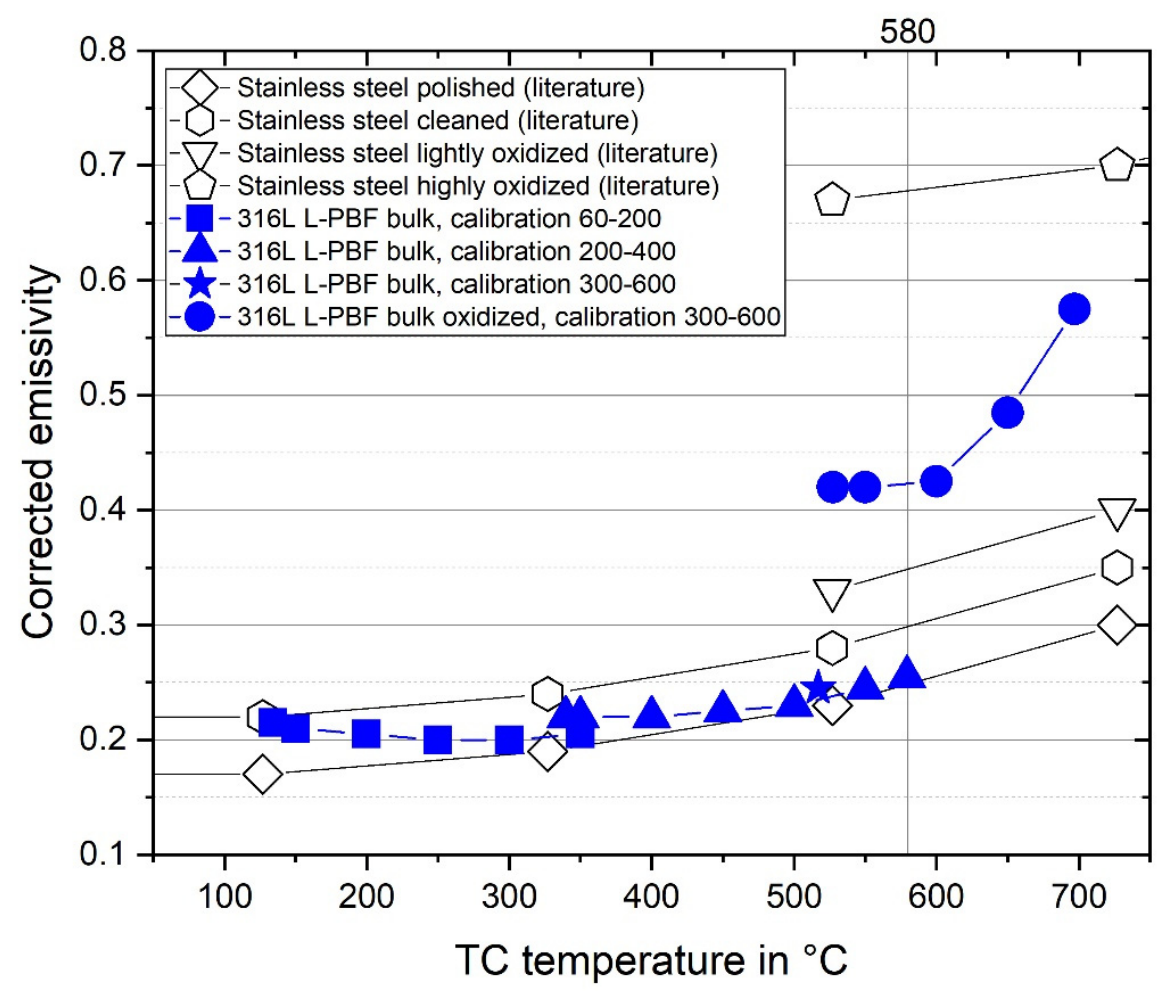

Figure 14. Corrected emissivity of 316L L-PBF bulk surface (blue symbols) over measured TC temperature. For comparison, temperature depend literature values of emissivity of stainless steel in different conditions (black hollow symbols) are added from [36].

\subsubsection{Corrected Emissivity of Powder Layers}

The same general changes between corrected emissivity values and apparent emissivity values, as discussed in the previous section for a 316L L-PBF bulk surface, also applied to the corrective analysis of the emissivity values of the two different powders. Figure 15 contains a comparison of the corrected emissivity values of 316L powder layer, IN718 powder layer and 316L L-PBF bulk surface. 


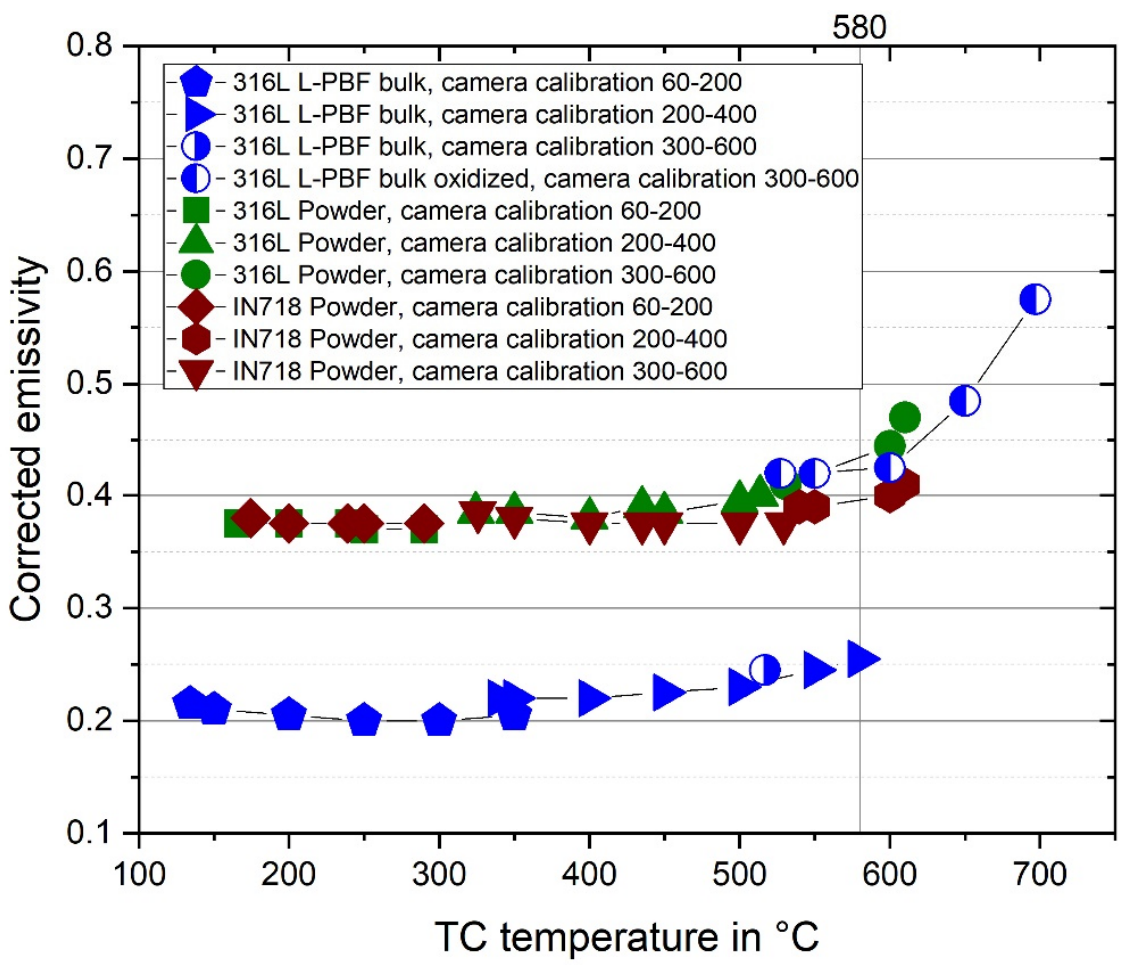

Figure 15. Corrected emissivity of 316L powder layer (green symbols) and of IN718 powder layer (brown symbols) and of 316L L-PBF bulk (blue symbols) over measured TC temperature.

The computed corrected emissivity of the 316L powder layer varied between $\varepsilon_{\text {corr }}=0.37$ and $\varepsilon_{\text {corr }}=0.4$ in the temperature region from $200{ }^{\circ} \mathrm{C}$ to $500{ }^{\circ} \mathrm{C}$ and between $\varepsilon_{\text {corr }}=0.4$ and $\varepsilon_{\text {corr }}=0.45$ in the temperature region between $500{ }^{\circ} \mathrm{C}$ and $600{ }^{\circ} \mathrm{C}$. The increase at higher temperatures was attributed to oxidation effects.

The computed corrected emissivity of the IN718 powder layer varied between $\varepsilon_{\text {corr }}=0.37$ and $\varepsilon_{\text {corr }}=0.38$ in the temperature region from $200{ }^{\circ} \mathrm{C}$ to $500{ }^{\circ} \mathrm{C}$ and between $\varepsilon_{\text {corr }}=0.38$ and $\varepsilon_{\text {corr }}=0.4$ in the temperature region between $500^{\circ} \mathrm{C}$ and $600^{\circ} \mathrm{C}$.

\subsection{Influence of Measurement Position}

No significant differences between the three positions of the heated sample could be found, as can be seen in Figure 16, which shows single temperature couples and the respective apparent emissivity values at a similar temperature, determined for the same calibration range. A comparison of the different positions was conducted using the camera calibration 200-400 measuring around a reference temperature of about $400{ }^{\circ} \mathrm{C}$. Please note that the calculated emissivity values did not contain any corrections, as discussed in Section 3.3, since a correction was not necessary for this relative comparison. It is also interesting to note that these measurements were conducted at a specimen which was heated up to $604{ }^{\circ} \mathrm{C}$ in air outside of the build chamber prior to these measurements. The surface temperature was above $570^{\circ} \mathrm{C}$ for about $480 \mathrm{~s}$. Therefore, the presented measurements stem from a slightly oxidized surface condition. The apparent emissivities under these conditions were: at position $1 \varepsilon_{\text {app }}=0.28$; at position $2 \varepsilon_{a p p}=0.28$; at position $3 \varepsilon_{a p p}=0.29$. The deviations of the emissivity values with regard to the different positions were within the measurement accuracy of the camera (see Section 3.5). According to published results on the angular dependence of emissivity $[20,35]$, this result was not surprising, as the angular tilt between the particular measurement sceneries for the different positions was small. However, the confirmation of comparable results irrespective of the position of the target object was important for further monitoring tasks. 


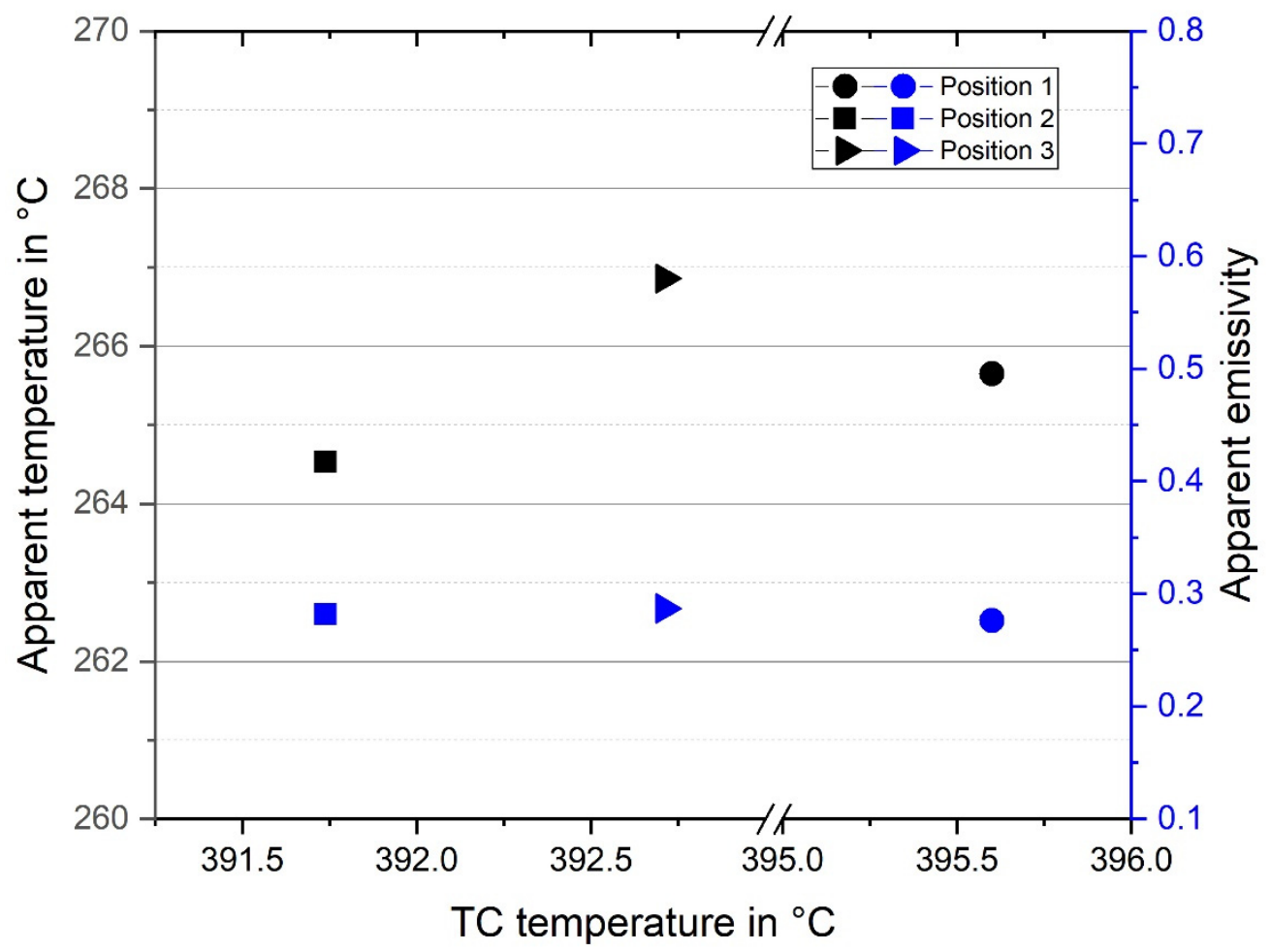

Figure 16. Apparent temperature and apparent emissivity of a 316L L-PBF bulk surface at three different positions within the build chamber according to the positions shown in Figure 7.

\subsection{Measurement Uncertainty}

As discussed above, unnoticed changes of the surface condition of the target object, e.g., an onset of oxidation layer growth, could lead to inaccuracies or misinterpretation. In addition, potential systematic measurement errors of the applied setup contributed to the measurement uncertainty. A rough quantification of the main contributing factors is given hereafter. The main factors contributing to the measurement uncertainty were identified as follows: accuracy of thermocouples, accuracy of MWIR camera, temperature heterogeneities over the target surface (with respect to TC and to IR camera values).

Accuracy of thermocouples: The standard limit of error of the used thermocouples was specified according to DIN EN 60594-1: $+/-2.5^{\circ} \mathrm{C}$ or $+/-0.75 \%$ [37].

Accuracy of the camera: The manufacturers' specifications of the MWIR camera allow for a deviation of up to $1 \%$ in the determination of apparent temperature in ${ }^{\circ} \mathrm{C}$ or $1{ }^{\circ} \mathrm{C}$, whichever is larger.

Temperature heterogeneities over the target surface: Figure 8 shows a temperature plot of the single thermocouples over a short period of time at temperatures between $520^{\circ} \mathrm{C}$ and $560{ }^{\circ} \mathrm{C}$. It was proposed to define the mean of TC1, TC 3 and TC4 as the surface temperature. This mean was taken in the discussion section without consideration of its standard deviation. The standard deviation of the temperatures of the three thermocouples was either smaller than $2.5^{\circ} \mathrm{C}$ or smaller than $0.75 \%$ of the measured temperature over the entire region of examined temperatures $\left(130{ }^{\circ} \mathrm{C}-700{ }^{\circ} \mathrm{C}\right)$. Only in the temperature region between $300^{\circ} \mathrm{C}$ and $470{ }^{\circ} \mathrm{C}$ were the standard deviations slightly higher, resulting in standard deviations of up to $1.1 \%$. To compare the temperature of the top surface and the temperature at the described positions TC1-TC4, one test specimen was heated up outside of the build chamber, which had two TCs on top of the upper surface, replacing TC2 and TC4. The temperature differences between these two TCs on top and TC1 and TC2 at the side surface were below the measuring errors mentioned above.

For a conservative estimation of the measuring error of the apparent temperature, the standard deviations of the max. and min. apparent temperature values of the four ROIs (see Figure 6) were 
calculated for the L-PBF bulk surface. They were up to $7.9 \%$ of the respective mean value in the calibration range 60-200; up to $4.2 \%$ in the calibration range $200-400$; and up to $6.5 \%$ in the calibration range 300-600. It was interesting to note that the standard deviation decreased drastically above an apparent temperature of approximately $500{ }^{\circ} \mathrm{C}$ to $2 \%$ in the measuring data of the calibration range 300-600. This corresponds well with the onset of oxidation and thus an increase of the emissivity above this value. Table 2 summarizes the resulting deviations per temperature regime. This results in a potential uncertainty of the emissivity determination of approximately 0.05 . Apart from these mentioned potential measuring errors, the separate measurements at three different positions (Sections 2.4.3 and 3.4) without significant deviations in apparent emissivity results demonstrate the good repeatability of the conducted measurements.

Table 2. Measurement uncertainties of temperature determination.

\begin{tabular}{ccc}
\hline $\begin{array}{c}\text { Target Object Temperature } \\
\text { in }{ }^{\circ} \mathrm{C}\end{array}$ & Deviations of TC Values & $\begin{array}{c}\text { Standard Deviation of the } \\
\text { Apparent Temperature Over } \\
\text { the Target Surface }\end{array}$ \\
\hline $130-300$ & $+/-2.5{ }^{\circ} \mathrm{C}$ & \begin{tabular}{c} 
calibration $60-200:+/-7.9 \%$ \\
\hline $300-470$
\end{tabular} \\
\hline \multirow{2}{*}{$470-700$} & $+/-1.1 \%$ & calibration $60-200:+/-7.9 \%$ \\
\hline & $+/-0.75 \%$ & calibration $200-400:+/-4.2 \%$ \\
\hline
\end{tabular}

Soldan [38] (p. 26) pointed out that potential measurement errors of thermographic measurements can occur due to incorrect focusing of the camera with regard to the target object. This is problematic in the context of unknown target objects, as there is no absolute measure for image sharpness [38]. In the frame of the thermographic setup of this study, the focusing of the IR camera was conducted by manual adjustment of the objective lens until the operator had the subjective impression of a sharp image in the live view mode of the software. This procedure had to be repeated when a calibration range of the camera was changed. Although the camera had a nearly perpendicular view of the target object and, therefore, a large lateral area at the same focus position, deviations from the ideal focus plane could not be completely precluded. However, the effect of defocused measurements is negligible when the region of interest does not contain edges, i.e., large temperature gradients. Here, only a plane surface area was taken into account for the measurements (compare Figure 6). A step-wise change of the z-position of the heating device of up to $10 \mathrm{~mm}$ difference in z-height revealed no differences in the mean apparent temperature. Thus, the manual focusing seemed to be reliable for the measuring procedure of this study.

\section{Conclusions}

An experimental temperature adjustment of an off-axis MWIR thermography setup, which was installed at a L-PBF machine, was conducted using the usual L-PBF working conditions. The apparent emissivity values for the specific setup were determined for two materials at two different conditions using the contact method: 316L L-PBF bulk material, 316L powder layer and IN718 powder layer. For this purpose, a heated reference device was placed inside a L-PBF build chamber. A corrective analysis considering transmission losses due to optical elements within the optical path as well as the affecting radiation of the surroundings revealed corrected emissivity values for the spectral range of $2 \mu \mathrm{m}$ to $5.7 \mu \mathrm{m}$. In the temperature region from approximately $150{ }^{\circ} \mathrm{C}$ to $580{ }^{\circ} \mathrm{C}$, where oxidation did not strongly effect the measurements, the corrected emissivity is in a range from 0.2 to 0.25 for a 316L L-PBF bulk surface, in a range from 0.37 to 0.45 for 316L powder layer, and in a range from 0.37 to 0.4 for IN718 powder layer. With the knowledge of these emissivity values, a real temperature determination for in situ thermographic measurements can be conducted. The findings will also 
be very useful for numerical simulations. Additionally, the heated reference device can be used for temperature adjustments of other thermographic setups that show differences, e.g., in the spectral sensitivity of the camera.

Author Contributions: Conceptualization, G.M.; methodology, G.M., S.N., and S.J.A.; validation, G.M., S.N., and S.J.A.; formal analysis, G.M., S.N. and S.J.A.; investigation, G.M., S.N., and S.J.A.; data curation, G.M., S.N.; writing—original draft preparation, G.M.; writing—review and editing, G.M., S.N., S.J.A., C.M. and K.H.; visualization, G.M., S.N.; supervision, K.H.; project administration, S.J.A., C.M. All authors have read and agreed to the published version of the manuscript.

Funding: This research was funded by BAM within the focus area Materials.

Acknowledgments: The authors would like to thank Mathias Röllig for his support in the verification of the camera calibration ranges against a black body radiator. The authors would also like to thank Matthias Weise for the measurement of the surface roughness.

Conflicts of Interest: The authors declare no conflict of interest. The funders had no role in the design of the study; in the collection, analyses, or interpretation of data; in the writing of the manuscript, or in the decision to publish the results.

\section{References}

1. Herzog, D.; Seyda, V.; Wycisk, E.; Emmelmann, C. Additive manufacturing of metals. Acta Mater. 2016, 117, 371-392. [CrossRef]

2. Grasso, M.; Colosimo, B.M. Process defects and in situ monitoring methods in metal powder bed fusion: A review. Meas. Sci. Technol. 2017, 28, 044005. [CrossRef]

3. Colosimo, B.M.; Grasso, M. In-situ monitoring in L-PBF: Opportunities and challenges. Procedia CIRP 2020, 94, 388-391. [CrossRef]

4. Ali, U.; Mahmoodkhani, Y.; Imani Shahabad, S.; Esmaeilizadeh, R.; Liravi, F.; Sheydaeian, E.; Huang, K.Y.; Marzbanrad, E.; Vlasea, M.; Toyserkani, E. On the measurement of relative powder-bed compaction density in powder-bed additive manufacturing processes. Mater. Des. 2018, 155, 495-501. [CrossRef]

5. Mohr, G.; Seeger, S.; Hilgenberg, K. Measurement of particle emissions in Laser Powder Bed Fusion (L-PBF) processes and its potential for in-situ process monitoring. In Proceedings of the Euro PM 2019, EPMA, Maastricht, The Netherlands, 13-16 October 2019.

6. Alberts, D.; Schwarze, D.; Witt, G. High speed melt pool \& laser power monitoring for selective laser melting $\left(\mathrm{SLM}^{\circledR}\right)$. In Proceedings of the 9th International Conference on Photonic Technologies LANE, Fürth, Germany, 19-22 September 2016.

7. Krauss, H.; Zeugner, T.; Zaeh, M.F. Layerwise Monitoring of the Selective Laser Melting Process by Thermography. Phys. Procedia 2014, 56, 64-71. [CrossRef]

8. Schmidt, M.; Merklein, M.; Bourell, D.; Dimitrov, D.; Hausotte, T.; Wegener, K.; Overmeyer, L.; Vollertsen, F.; Levy, G.N. Laser based additive manufacturing in industry and academia. CIRP Ann. 2017, 66, 561-583. [CrossRef]

9. Lane, B.; Moylan, S.; Whitenton, E.; Ma, L. Thermographic Measurements of the Commercial Laser Powder Bed Fusion Process at NIST. Rapid Prototyp. J. 2016, 22, 778-787. [CrossRef] [PubMed]

10. Heigel, J.C.; Lane, B.M. Measurement of the Melt Pool Length during Single Scan Tracks in a Commercial Laser Powder Bed Fusion Process. J. Manuf. Sci. Eng. 2018, 140, 051012. [CrossRef]

11. Bartlett, J.L.; Heim, F.M.; Murty, Y.V.; Li, X. In situ defect detection in selective laser melting via full-field infrared thermography. Addit. Manuf. 2018, 24, 595-605. [CrossRef]

12. Mohr, G.; Altenburg, S.J.; Ulbricht, A.; Heinrich, P.; Baum, D.; Maierhofer, C.; Hilgenberg, K. In-Situ Defect Detection in Laser Powder Bed Fusion by Using Thermography and Optical Tomography-Comparison to Computed Tomography. Metals 2020, 10, 103. [CrossRef]

13. Mohr, G.; Altenburg, S.J.; Hilgenberg, K. Effects of inter layer time and build height on resulting properties of 316L stainless steel processed by laser powder bed fusion. Addit. Manuf. 2020, 32, 101080. [CrossRef]

14. Williams, R.J.; Piglione, A.; Rønneberg, T.; Jones, C.; Pham, M.S.; Davies, C.M.; Hooper, P.A. In situ thermography for laser powder bed fusion: Effects of layer temperature on porosity, microstructure and mechanical properties. Addit. Manuf. 2019, 30, 100880. [CrossRef] 
15. Usamentiaga, R.; Venegas, P.; Guerediaga, J.; Vega, L.; Molleda, J.; Bulnes, F.G. Infrared thermography for temperature measurement and non-destructive testing. Sensors 2014, 14, 12305-12348. [CrossRef] [PubMed]

16. Lough, C.S.; Wang, X.; Smith, C.C.; Adeniji, O.; Landers, R.G.; Bristow, D.A.; Kinzel, E.C. Use of SWIR Imaging to Monitor Layer-to-Layer Part Quality during SLM of 304L Stainless Steel. In Proceedings of the 29th Annual International Solid Freeform Fabrication Symposium, Austin, TX, USA, 13-15 August 2018.

17. Mohr, G.; Scheuschner, N.; Hilgenberg, K. In situ heat accumulation by geometrical features obstructing heat flux and by reduced inter layer times in laser powder bed fusion of AISI 316L stainless steel. CIRP Proceedia 2020, 94, 155-160. [CrossRef]

18. Khan, K.; Mohr, G.; Hilgenberg, K.; De, A. Probing a novel heat source model and adaptive remeshing technique to simulate laser powder bed fusion with experimental validation. Comput. Mater. Sci. 2020, 181, 109752. [CrossRef]

19. Schuster, N.; Kolobrodov, V.G. Infrarotthermographie; Wiley-VCH: Weinheim, Germany, 2004.

20. Vollmer, M.; Möllmann, K.P. Infrared Thermal Imaging: Fundamentals, Research and Applications; Wiley-VCH: Weinheim, Germany, 2017.

21. Siegel, R.; Howell, J.R.; Lohrengel, J. Wärme- und Stoffübertragung. Teil 1: Grundlagen und Materialeigenschaften; Springer: Berlin, Germany, 1988.

22. Glückert, U. Erfassung und Messung von Wärmestrahlung. Eine Praktische Einführung in die Pyrometrie und Thermographie; Franzis: Munich, Germany, 1992.

23. Doubenskaia, M.; Pavlov, M.; Grigoriev, S.; Smurov, I. Definition of brightness temperature and restoration of true temperature in laser cladding using infrared camera. Surf. Coat. Technol. 2013, 220, 244-247. [CrossRef]

24. Yadroitsev, I.; Krakhmalev, P.; Yadroitsava, I. Selective laser melting of Ti6Al4V alloy for biomedical applications: Temperature monitoring and microstructural evolution. J. Alloys Compd. 2014, 583, 404-409. [CrossRef]

25. Heigel, J.C.; Whitenton, E. Measurement of thermal processing variability in powder bed fusion. In Proceedings of the 2018 ASPE and Euspen Summer Topical Meeting-Advancing Precision in Additive Manufacturing, Berkeley, CA, USA, 22-25 July 2018.

26. Heigel, J.; Lane, B.; Moylan, S. Variation of Emittivity with Powder Bed Fusion Build Parameters. In Proceedings of the 2016 Annual International SFF Symposium, Austin, TX, USA, 8-10 August 2016.

27. Hakiki, N.; Montemor, M.; Ferreira, M.; da Cunha Belo, M. Semiconducting properties of thermally grown oxide films on AISI 304 stainless steel. Corros. Sci. 2000, 42, 687-702. [CrossRef]

28. Kämmerer, B. Abhängigkeit der Korrosionsbeständigkeit von der Chemischen Oberflächenzusammensetzung von Chromstählen; Universität Augsburg: Augsburg, Germany, 2012.

29. Joachim, J. Untersuchung von Oxidationsprozessen an Oberflächen von FeCr-Legierungen und Austenitstahl mittels Röntgenabsorptionsspektroskopie unter Streifendem Einfall; Rheinische Friedrich-Wilhelms-Universität Bonn: Bonn, Germany, 2003.

30. Iuchi, T.; Furukawa, T.; Wada, S. Emissivity modeling of metals during the growth of oxide film and comparison of the model with experimental results. Appl. Opt. 2003, 42, 2317-2326. [CrossRef]

31. Zauner, G.; Mayrhofer, F.; Hendorfer, G. Optical characterization of growing thin films at high temperatures by analysis of near infrared emissivity variations using CCD thermal imaging. In Proceedings of the 2010 International Conference on Quantitative InfraRed Thermography, Quebec, QC, Canada, 24-29 June 2010.

32. Del Campo, L.; Pérez-Sáez, R.B.; Tello, M.J. Iron oxidation kinetics study by using infrared spectral emissivity measurements below $570{ }^{\circ} \mathrm{C}$. Corros. Sci. 2008, 50, 194-199. [CrossRef]

33. Krauss, H.; Eschey, C.; Zaeh, M.F. Thermography for Monitoring the Selective Laser Metling Process. In Proceedings of the Solid Freeform Fabrication Symposium; University of Texas: Austin, TX, USA, 2012; pp. 999-1014.

34. Altenburg, S.J.; Straße, A.; Gumenyuk, A.; Maierhofer, C. In-situ monitoring of a laser metal deposition (LMD) process: Comparison of MWIR, SWIR and high-speed NIR thermography. Quant. InfraRed Thermogr. J. 2020, 1-18. [CrossRef]

35. Del Campo, L.; Pérez-Sáez, R.B.; González-Fernández, L.; Esquisabel, X.; Fernández, I.; González-Martín, P.; Tello, M.J. Emissivity measurements on aeronautical alloys. J. Alloys Compd. 2010, 489, 482-487. [CrossRef]

36. Incropera, F.P.; DeWitt, D.P.; Bergman, T.L.; Lavine, A.S. Fundamentals of Heat and Mass Transfer, 6th ed.; John Wiley \& Sons: Hoboken, NJ, USA, 2007. 
37. Deutsches Institut für Normung (DIN). DIN EN 60584-1: Thermocouples_Part 1: EMF Specifications and Tolerances; DIN: Berlin, Germany, 2014.

38. Soldan, S. Sensordatenfusionsansätze in der Thermografie zur Verbesserung der Messergebnisse; Universität Kassel: Kassel, Germany, 2014.

Publisher's Note: MDPI stays neutral with regard to jurisdictional claims in published maps and institutional affiliations.

(C) 2020 by the authors. Licensee MDPI, Basel, Switzerland. This article is an open access article distributed under the terms and conditions of the Creative Commons Attribution (CC BY) license (http://creativecommons.org/licenses/by/4.0/). 